\title{
The vertical structure of annual wave energy flux in the tropical Indian Ocean
}

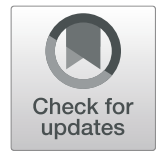

Zimeng $\mathrm{Li}^{1^{*}}$, Hidenori Aiki ${ }^{2,3^{*}}$, Motoki Nagura ${ }^{4}$ and Tomomichi Ogata ${ }^{3}$

\begin{abstract}
A recently developed energy flux diagnosis scheme, which incorporates a smooth connection between the tropical and subtropical zones, is used in the present study to investigate vertically propagating waves in the tropical Indian Ocean $(I O)$ based on the result of a linear, continuously stratified ocean model driven by climatological wind forcing. This extended diagnosis reveals deep-reaching eastward energy fluxes at the equator which develop four times per year and are associated with equatorial Kelvin waves (KWs) generated by semiannual winds. The authors find that the downward transfer of wave energy is particularly deep in the southern Bay of Bengal (SBoB). This downward flux is attributed to off-equatorial Rossby waves and appears four times per year, maximizing its amplitude during November-December. Southwesterly winds in the Arabian Sea intensify eastward energy flux of KWs at mid-depth, which maximizes in amplitude in August. This is contrastive to KW energy flux at the surface which peaks in May. These mid-depth equatorial KW packets subsequently arrive at the eastern boundary of the IO and are diffracted poleward to produce downward energy flux in November and December detected in the SBoB.
\end{abstract}

Keywords: Indian Ocean, Kelvin wave, Rossby wave, Seasonal variation, Vertical structure, Wave energy

\section{Introduction}

In the tropical regions, the dynamics of the atmosphereocean interactions dictating the growth and morphology of large-scale surface currents strongly depend on the subsurface oceanic structure. In turn, variability in the surface currents themselves can induce deep and persistent flows which remain trapped along the equator (Luyten and Swallow 1976; Hayes and Milburn 1979; McCreary 1984; Rothstein et al. 1985; Kessler and McCreary 1993; Dewitte and Reverdin 2000). In the central equatorial Indian Ocean (IO), wind forcing develops on a semiannual timescale. Further to the west and in the regions off the equator, the monsoonal phase transition produces a seasonal cycle in wind forcing (Reppin et al. 1999; Schott and McCreary 2001). The former semiannual wind forcing induces equatorial Kelvin waves (KWs) with a downwelling

\footnotetext{
*Correspondence: lizimeng1995@gmail.com; aiki@nagoya-u.jp

${ }^{1}$ Graduate School of Environmental Studies, Nagoya University, Furo-cho,

Chikusa-ku, Nagoya 464-8601, Japan

${ }^{2}$ Institute for Space-Earth Environmental Research, Nagoya University,

Furo-cho, Chikusa-ku, Nagoya 464-8601, Japan

Full list of author information is available at the end of the article
}

phase in the surface layer in both boreal spring and autumn and a corresponding upwelling phase in both boreal winter and summer, leading to an eastward transfer of wave energy four times per year ( $\mathrm{Li}$ and Aiki 2020, hereafter LA20). Striking the eastern boundary of the tropical IO, KWs are first retro-reflected, then diffracted poleward and subsequently radiate westward-propagating equatorial and midlatitude Rossby waves (RWs) (Mark and Huang 2004; Han 2005; Fu 2007).

Previous studies have investigated the vertical propagation of equatorial KWs and RWs in the Pacific and Atlantic Oceans on intraseasonal to interannual time scales (McPhaden 1982; Lucas and Firing 1985; McPhaden and Ripa 1990; Kessler and McCreary 1993; Brandt and Eden 2005; Thierry et al. 2006; Ishizaki et al. 2014). Vertically propagating waves are also observed in the tropical IO. Owing to the dominance of semiannual wind forcing, variability in mid-depth of the equatorial IO below the main pycnocline is characterized by semiannual variability (Luyten and Roemmich 1982; Nagura and McPhaden 2016; Huang et al. 2018a, b; Zanowski and Johnson 2019; Chen et al. 2020). They consist of equatorial KWs and long RWs, which carry energy to the east and to 
the depth, and to the west and to the depth, respectively. Waves are reflected at the eastern and western boundaries of the IO, and boundary-generated waves further propagate downward (Nagura and McPhaden 2016; Huang et al. 2019). In particular, mooring observations in the southern Bay of Bengal (SBoB) at $5^{\circ} \mathrm{N}, 90.5^{\circ} \mathrm{E}$ show a robust half-year cycle between 200 and $1200 \mathrm{~m}$ depth (Huang et al. 2019). The subsurface mooring at the same location used in Chen et al. (2017) reveals remarkable intraseasonal meridional currents across $\mathrm{SBoB}$ that are attributed to westward-propagating RWs. In the off-equatorial region, variability below the pycnocline has annual periodicity, owing to the predominance of annual wind forcing related to monsoon (Johnson 2011; Nagura 2018; Huang et al. 2019).

These previous studies examined vertical propagation of waves using ray tracing technique and/or vertical mode decomposition. Ray tracing technique requires the assumption that the WKB approximation is valid (i.e., the vertical scale of variation in buoyancy frequency is larger than vertical wavelength of waves). This assumption is generally satisfied below the pycnocline, but not in and above the pycnocline. Owing to this, energy propagation cannot be traced from the surface, where winds excite wave energy, to the depth below the pycnocline using the ray tracing technique. This raises an essential difficulty in interpreting the generation mechanism of mid-depth waves. Vertical mode decomposition does not require such an assumption, but vertically propagating waves consist of multiple baroclinic modes (Table 1), and examination of each baroclinic mode is not informative about vertical propagation. An alternative is sensitivity experiments using a numerical model, but this method is relatively expensive computationally.

These problems can be solved by the use of energy flux newly defined by Aiki et al. (2017; hereafter AGC17) and Aiki et al. (under revision in Journal of the Atmospheric Sciences, hereafter JAS2021). Their scheme does not use the WKB approximation and is applicable seamlessly to depths above, in, and below the pycnocline. It does not require quasi-geostrophy and covers variability both in the equatorial and subtropical regions.
It does not require Fourier transform either and thus can be used in coastal regions. The scheme is diagnostic and provides a computationally cheaper way compared with sensitivity experiments using an elaborated numerical model. The AGC17 scheme allowed Ogata and Aiki (2019), LA20, Song and Aiki (2020), and Toyoda et al. (2021) to obtain wholly new perspectives on the horizontal transfer routes of waves in the tropical oceans. We extend their work to a three-dimensional system and describe vertical wave propagation.

The depth-dependent version of the seamless AGC17 scheme has not been applied to the analysis of oceanic waves before the present study. Our initial focus will mainly be on seasonal variability in the $\mathrm{IO}$, while interannual variations will be investigated in the future work. The manuscript is laid out in the following fashion: Section 2 describes the formulation of an adopted model, method for energy flux computation, and temporal and spatial characteristics of simulated fields. Section 3 provides an analysis of the vertical structure of energy fluxes associated with KWs and RWs, while Section 4 gives a summary of the main results.

\section{Materials and methods}

AGC17 employed a single-layer system based on the shallow-water equations to derive depth-independent expressions of the energy flux. As it has the advantage of a smooth tropical-subtropical transition, the AGC17 scheme can effectively determine the horizontal distribution of energy flux pointing in the direction of group velocity of waves. JAS2021 has extended the formulation of AGC17 to cover the case of a baroclinic system in the atmosphere. Their essential contribution is the derivation of the exact expression of the vertical component of energy flux (this is not described in the present manuscript). The expressions given below for the horizontal component of depth-dependent energy flux represent a straightforward extension of the content of AGC17 and are summarized below by the adoption of an oceanic framework that the general reader should find convenient.

Table 1 List of experiment parameters. The basin mode period is defined as $4 L / c^{(n)}$ where $L=6110 \mathrm{~km}$ is the zonal distance of the Indian Ocean at the equator (from 45 to $100^{\circ} \mathrm{E}$ ). The wind-coupling thickness is defined as $\sqrt{h_{\text {mix }} H_{\text {bottom }}} / a^{(n)}$, where $h_{\text {mix }}=35 \mathrm{~m}$ and $H_{\text {bottom }}=5500 \mathrm{~m}$

\begin{tabular}{|c|c|c|c|c|c|c|}
\hline Baroclinic mode & $1 \mathrm{st}$ & 2nd & 3 rd & 4th & 5th & 6th \\
\hline Gravity wave speed (m/s) & 2.63 & 1.57 & 0.956 & 0.706 & 0.557 & 0.467 \\
\hline Equatorial deformation radius (km) & 339 & 262 & 205 & 176 & 156 & 143 \\
\hline Equatorial inertial period (day) & 9.4 & 12.1 & 15.6 & 18.1 & 20.4 & 22.3 \\
\hline Basin mode period (year) & 0.29 & 0.49 & 0.81 & 1.1 & 1.39 & 1.66 \\
\hline$a^{(n)}$ (non-dimensional) & 0.39 & 0.41 & 0.27 & 0.29 & 0.23 & 0.22 \\
\hline Wind-coupling thickness (m) & 1123 & 1062 & 1644 & 1505 & 1933 & 1955 \\
\hline
\end{tabular}




\subsection{Formulation of wave energy flux}

In order to investigate the vertical structure of energy transfers, we aim to derive depth-dependent expressions of energy flux. We use the primitive equations for a Boussinesq fluid on an equatorial $\beta$ plane (Gill 1982) appropriate for linear waves propagating in a rotating frame of reference and with zero mean flow. Let $x, y, z$, and $t$ define independent variables in a Cartesian coordinate system and increase eastward, northward, and vertically upward respectively. The quantities $u, v$, and $w$ represent the corresponding three-dimensional components of velocity (a full list of variables is given in Table 2). The equations may then be written as

$$
\begin{aligned}
& \frac{\partial u}{\partial t}-f v+\frac{\partial \Phi}{\partial x}=0, \\
& \frac{\partial v}{\partial t}+f u+\frac{\partial \Phi}{\partial y}=0, \\
& \frac{\partial \Phi}{\partial z}=-g \frac{\rho}{\rho_{0}}, \\
& w=\frac{-1}{N^{2}} \frac{\partial^{2} \Phi}{\partial z \partial t}, \\
& N^{2}=-\frac{g}{\rho_{0}} \frac{d \bar{\rho}}{d z}, \\
& \frac{\partial u}{\partial x}+\frac{\partial v}{\partial y}+\frac{\partial w}{\partial z}=0,
\end{aligned}
$$

Table 2 List of symbols used in Section 2.1, where A is arbitrary quantities written dimensionally. The coordinate axes $x, y, z$ increase eastward, northward, and vertically upward, respectively

\begin{tabular}{ll}
\hline$f=f_{0}+\beta y$ & Coriolis parameter \\
$N=\sqrt{-\left(g / \rho_{0}\right)(d \bar{\rho} / d z)}$ & Buoyancy frequency \\
$x, y, z, t$ & Cartesian coordinates \\
$\langle\langle a, b, c\rangle\rangle$ & Vector with $x, y$ and $z$-axis components $a, b$, \\
$U \equiv\langle\langle u, v, w\rangle\rangle$ & and $c$ \\
$\nabla \equiv\langle\langle\partial x, \partial y, \partial z\rangle\rangle$ & Velocity vector \\
$\Phi$ & Gradient operator \\
$q$ & Geopotential \\
$\varphi$ & Potential vorticity $q \equiv v_{x}-u_{y}+\left[\left(f / N^{2}\right) \Phi_{z}\right]_{z}$ \\
$\varphi^{a p p}$ & Solution of (6a) \\
$\left.\overline{\left(u^{2}+v^{2}+\Phi_{z}^{2} / N^{2}\right.}\right) / 2$ & Solution of (7a) \\
$\mu=k x+m z-\omega t$ & Wave energy density \\
$k$ & Wave phase \\
$m$ & Zonal wavenumber \\
$\omega$ & Vertical wavenumber \\
$\bar{A}$ & Wave frequency \\
\hline
\end{tabular}

where $f=f_{0}+\beta y$ is the Coriolis parameter, $\Phi=\Phi(x, y, z$, $t$ ) corresponds to geopotential, and $\rho=\rho(x, y, z, t)$ is the perturbation of potential density. The symbols $N=N(z)$ and $g$ are the buoyancy frequency and the acceleration owing to gravity, respectively. The symbols $\rho_{0}$ and $\bar{\rho}(z)$ represent the reference density and the background density, respectively. Manipulation of (1a)-(1f) yields a prognostic equation for potential vorticity (PV: symbolized as $q$ ) to read

$$
\frac{\partial}{\partial t} \underbrace{\left[\frac{\partial v}{\partial x}-\frac{\partial u}{\partial y}+\frac{\partial}{\partial z}\left(\frac{f}{N^{2}} \frac{\partial \Phi}{\partial z}\right)\right]}_{\equiv q}+v \beta=0 .
$$

This relation is generally applicable to waves at all latitudes, such as midlatitude RWs, midlatitude inertiagravity waves (IGWs), and equatorial waves (i.e., equatorial RWs and IGWs, equatorial Rossby-gravity waves (RGWs, i.e., Yanai waves) and equatorial KWs (Matsuno 1966; Yanai and Maruyama 1966), if we applied it to an equatorial $\beta$ plane $\left(f_{0}=0\right)$ ). Equatorial KWs (i.e., $v=0$ ) are characterized by $q=0$. From (1a) $-(1 \mathrm{c})$, the wave energy density may be represented in prognostic fashion by

$$
\begin{aligned}
\frac{\partial}{\partial t} & \frac{1}{2}\left[u^{2}+v^{2}+\frac{1}{N^{2}}\left(\frac{\partial \Phi}{\partial z}\right)^{2}\right] \\
& +\nabla \cdot\langle\langle\overline{u \Phi}, \overline{v \Phi}, \overline{w \Phi}\rangle\rangle \\
& =0
\end{aligned}
$$

where $\nabla \equiv\left\langle\left\langle\frac{\partial}{\partial x}, \frac{\partial}{\partial y}, \frac{\partial}{\partial z}\right\rangle\right\rangle$ and the overbar signifies phase averaging (i.e., for a sinusoidal wave, $\bar{A}=0$ for $A=u, v$, $w$ and $\Phi$ ), or low-pass time filtering (considering this case, we retain the local time derivative in (3a), thereby permitting slow time variations in the general case). The energy flux vector in (3a)

$$
\overline{\mathrm{U} \Phi}=\langle\langle\bar{u} \Phi, \overline{v \Phi}, \overline{w \Phi}\rangle\rangle
$$

is codirectional with the group velocity of midlatitude IGWs in the atmosphere and ocean (Gill 1982). However, the energy flux of (3b) is not aligned with the group velocity of midlatitude RWs (Longuet-Higgins 1964).

In order to obtain an expression of the energy flux that is codirectional with group velocity of all wave types, AGC17 (and also JAS2021) has revisited the equations to define energy flux of both equatorial and midlatitude waves. The derivation is briefly described below using linear waves on an equatorial $\beta$ plane and zero mean flow. Let $k, m$, and $\omega$ be zonal and vertical wavenumbers and wave frequency, respectively. The zonal component of group velocity of equatorial waves may be written as 


$$
\frac{\partial \omega}{\partial k}=\frac{2 \omega^{2}+\omega / k}{2 \omega^{3} m^{2} /\left(k N^{2}\right)+1},
$$

which has been written in a dimensional form and $m$ denotes vertical wavenumber.

The group velocity times wave energy density is rewritten in a depth-dependent framework as

$$
\begin{aligned}
\frac{\partial \omega}{\partial k} & \frac{1}{2}\left[u^{2}+v^{2}+\frac{1}{N^{2}}\left(\frac{\partial \Phi}{\partial z}\right)^{2}\right] \\
& =\overline{u \Phi}+\frac{\partial}{\partial y}\left(\frac{\overline{\Phi \phi}}{2}+\frac{1}{\beta} \frac{\partial^{2} u}{\partial t^{2}} \phi\right), \\
\phi & \equiv \frac{-v_{\mu}}{k+2 \omega^{3} m^{2} /\left(\beta N^{2}\right)},
\end{aligned}
$$

where the scalar quantity $\phi$ may be referred to as pseudo-streamfunction and the subscript $\mu$ signifies partial derivative with respect to wave phase (details are given in Supplementary Material of this manuscript). We note that, for any type of equatorial waves, there is a precise identity between the meridional profile of zonal energy flux on the right-hand side of (5a) and the quantity $(\partial \omega / \partial k)\left(\overline{u^{2}+v^{2}+\Phi_{z}^{2} / N^{2}}\right) / 2$, which is illustrated in JAS2021. The definition of $\phi$ in (5b) makes use of a Fourier expansion. In a depth-dependent form, (5b) can be reformulated such that the parameters $k, m$, and $\omega$ are absent, which yields an inversion equation for PV to read

$$
\begin{aligned}
& \left(\frac{\partial^{2}}{\partial x^{2}}+\frac{\partial^{2}}{\partial y^{2}}\right) \phi \\
& \quad+\frac{\partial}{\partial z}\left[\left(\frac{1}{N^{2}}\right) \frac{\partial}{\partial z}\left(f^{2} \phi+3 \frac{\partial^{2}}{\partial t^{2}} \phi\right)\right] \\
& \quad=q
\end{aligned}
$$

where $q$ has been defined in (2). The three-dimensional components of wave energy flux are written in a vector form as,

$$
\overline{\mathrm{U} \Phi}+\left\langle\left\langle\frac{\partial}{\partial y}\left(\frac{\overline{\Phi \phi}}{2}+\frac{1}{\beta} \frac{\overline{\partial^{2} u}}{\partial t^{2}} \phi\right),-\frac{\partial}{\partial x}\left(\frac{\overline{\Phi \phi}}{2}+\frac{1}{\beta} \overline{\partial^{2} u} \frac{\partial t^{2}}{}\right), 0\right\rangle\right\rangle,
$$

whose horizontal component is referred to as the level 0 (i.e. exact) expression for waves at all latitudes. The vertical component of (6b) represents a rough approximation of the vertical group velocity times wave energy for equatorial waves and its exact expression for midlatitude waves. See JAS2021 for the details of (6a)-(6b).

AGC17 considered eliminating the term representing the second-order time derivative from their exact inversion equation for PV. This corresponds to (6a) in the present study. Let $\phi^{a p p}$ be the solution of the approximated PV inversion equation to read,

$$
\left(\frac{\partial^{2}}{\partial x^{2}}+\frac{\partial^{2}}{\partial y^{2}}\right) \phi^{a p p}+\frac{\partial}{\partial z}\left(\frac{f^{2}}{N^{2}} \frac{\partial}{\partial z} \phi^{a p p}\right)=q,
$$

which may be solved using the set of a Dirichlet boundary condition $\left(\phi^{\mathrm{app}}=0\right)$ at coastlines and bottom topography and a Neumann boundary condition $\left(\partial \phi^{a p p} / \partial z=0\right)$ at the sea surface. What AGC17 has called the level-2 (i.e., approximate) expression for energy flux is extended here to a depth-dependent form as

$$
\overline{\mathrm{U} \Phi}+\left\langle\left\langle\frac{\partial}{\partial y}\left(\overline{\frac{\phi^{a p p} \Phi}{2}}\right),-\frac{\partial}{\partial x}\left(\overline{\frac{\phi^{a p p} \Phi}{2}}\right), 0\right\rangle\right\rangle,
$$

which has been used in the overall model analyses of the present study.

Equation (7b) may be applied also to equatorial KWs for which $\overline{\mathrm{U} \Phi}$ becomes identical to the product of group velocity and wave energy density. Namely, no term for additional rotational flux is present. A characteristic of KWs is $v=0$, which yields $q=0$ following (2). Since the right-hand side of (7a) vanishes, the expression of energy flux for KWs given in (7b) reduces to $\bar{U} \Phi$. This result is consistent with the nature of gravity waves.

We consider the Helmholtz decomposition of the level-2 wave energy flux to read,

$$
\begin{aligned}
& -\frac{\partial}{\partial y} R-\frac{\partial}{\partial x} D=\rho_{0} \overline{u \Phi}+\rho_{0} \frac{\partial}{\partial y}\left(\overline{\phi^{a p p} \Phi} / 2\right), \\
& +\frac{\partial}{\partial x} R-\frac{\partial}{\partial y} D=\rho_{0} \overline{\nu \Phi}-\rho_{0} \frac{\partial}{\partial x}\left(\overline{\phi^{a p p} \Phi} / 2\right),
\end{aligned}
$$

where the scalar quantities $R$ corresponds to the rotational component of energy flux and is referred to as energy flux streamfunction. The quantity $D$ in $(8 \mathrm{a})-(8 \mathrm{~b})$ is associated with the divergent components of energy flux and is referred to as energy flux potential. The energy flux potential becomes positive in regions where winds supply wave energy (see Appendix for the expression of energy input by winds). The energy flux potential becomes negative in regions where wave energy is dissipated. As shown by LA20, the distribution of potential is smooth and nicely shows large-scale characteristics, in contrast to the distributions of the wind input and dissipation terms that manifest small-scale and locally signindefinite signals. This is the reason why the present study recommends to use the distribution of the energy flux potential, instead of its pre-inversion terms. We shall show the distribution of the energy flux potential and streamfunction, as given by $(8 \mathrm{a})-(8 \mathrm{~b})$, in the IO later in the manuscript. 


\subsection{Model setup}

We simulated climatological variability in the IO using a classical linear ocean model (LOM, see Appendix for details). This model yields both the three-dimensional and baroclinic-mode profiles of velocity vector and geopotential, that is aimed at facilitating our analysis of simulated wave dynamics. This kind of model has been used by previous studies to examine vertical propagation of waves (Huang et al. 2018a, 2019, 2020; Chen et al. 2020) and is dynamically consistent with our formulation of energy flux that is derived from linear equations (Eq. (1a)-(1f)). The wind forcing for the model is derived from the $10 \mathrm{~m}$ wind data of the European Centre for Medium-Range Weather Forecasts Reanalysis (ECMWF ERA-40) by applying the Large and Pond (1981) bulk formula to wind data from September 1957 to August 2002. While the experiments described in LA20 assumed no motion near the ocean bottom and examined the first three baroclinic modes, here, we assume a free-slip bottom boundary condition (Chelton and Schlax 1996) as in traditional studies and focus on the first six baroclinic modes. This change of model setup is required in order to investigate the vertical propagation of waves in the present study. Each of our six numerical experiments involved integration over a period of 20 years (inclusive of the spin-up phase from a state of no motion). Investigation of the fundamental baroclinic modes begins when the system reaches a confirmed climatological equilibrium. The subsequent analysis is then based on the final 100 "snapshots" of model output. Since these are separated by 3.65 days, we make use of data from the last year of each run. Below, all results are shown in the depth coordinate, which are reconstructed from the model outputs of the first six baroclinic modes. The result of the LOM experiment is justified in the next subsection by comparing with the output from a highresolution climatological Ocean General Circulation Model (OGCM) simulation for the semi-global ocean. We have used monthly current and wind stress data derived from the OGCM For the Earth Simulator (OFES) forced by National Centers for Environmental Prediction reanalysis winds (Masumoto et al. 2004). OFES is on the basis of Modular Ocean Model version 3. The output is monthly mean during the last 6 years (from 45 to 50 years) of 50 year climatological integration with a horizontal resolution of $0.1^{\circ} \times 0.1^{\circ}$ and 54 vertical levels.

\subsection{Simulated currents and waves}

We first briefly outline some key features from the LOM experiment. The model reproduces the Somali jet, which flows along the East African coast and is driven by largescale seasonal monsoonal winds, and the Wyrtki (1973) jet (e.g., Nagura and McPhaden 2010a), which represents an along-equator response to semiannual westerly winds during the monsoon transition period (Fig. 1). To investigate how the monsoon circulation affects velocity variability, we have constructed the longitude-depth sections of zonal velocity along the equator (left panels in Fig. 2) and the latitude-depth sections of zonal velocity at $70^{\circ} \mathrm{E}$ (right panels in Fig. 2). Semiannual winds induce east-upward tilt in the phase line of zonal velocity (yellow line in Fig. 2a, e), which can explain the formation of the Wyrtki jet in the following monsoon transition period. A semiannual variation of baroclinic flow is dominant below about $200 \mathrm{~m}$ depth along the equator in response to the surface-layer Wyrtki jets. An eastward undercurrent near $150 \mathrm{~m}$ depth along the equator in February (Fig. 2a), referred to as Equatorial Undercurrent, is generated by equatorial KWs and long RWs, as investigated by Chen et al. (2015a, 2019). Simulated zonal velocity along $70^{\circ} \mathrm{E}$ is trapped at the equator with a vertical phase propagation, which coincides with the latitude-depth plots of climatological zonal currents along $80^{\circ} \mathrm{E}$ using ocean reanalysis data in Huang et al. (2018b). They pointed out that vertically propagating RWs generated by the reflection of wind-forced KWs at the eastern boundary of IO are responsible for the vertical phase propagation of mid-depth zonal currents on the basis of mooring and reanalysis data, and this conclusion was further confirmed by Zanowski and Johnson (2019) using velocity and isotherm displacement obtained from Argo floats.

We compare the seasonal anomalies of current and wind stress derived from OFES (Fig. 3a, b) and our climatological model experiments (Fig. 3c, d). The Hovmöller longitudetime diagrams along the equator at the sea surface indicate that the eastward-propagating KW signals are less pronounced in surface zonal velocity and more pronounced in geopotential anomaly (Fig. 3a, c, e). Semiannual winds cause velocity reversals four times per year. This is consistent with Yu and McPhaden (1999), Ding et al. (2009) and Nagura and McPhaden (2010a, b), who pointed out that variability in surface zonal velocity along the equator is dominated by RWs, and that in SSH by equatorial KWs. Geopotential anomalies are positive near the surface during boreal spring and fall, which are associated with wind-forced downwelling KWs. Both the horizontal section at the surface (Fig. 3a, c) and the vertical section in the upper $2000 \mathrm{~m}$ (Fig. 3b, d) of zonal velocity derived from OGCM (Fig. 3a, b) and simulated by LOM (Fig. 3c, d) show upward phase signals and reversals of zonal currents four times per year with a noticeable semiannual cycle. These results agree with Huang et al. (2018a) and Chen et al. (2020), who demonstrated that the semiannual cycle is the predominant feature of mid-depth zonal currents in the equatorial IO. Geopotential anomalies (colors in Fig. 3f) are also characterized by the semiannual cycle with an upward phase propagation, which is attributable to windgenerated upwelling (during the monsoon seasons) and 

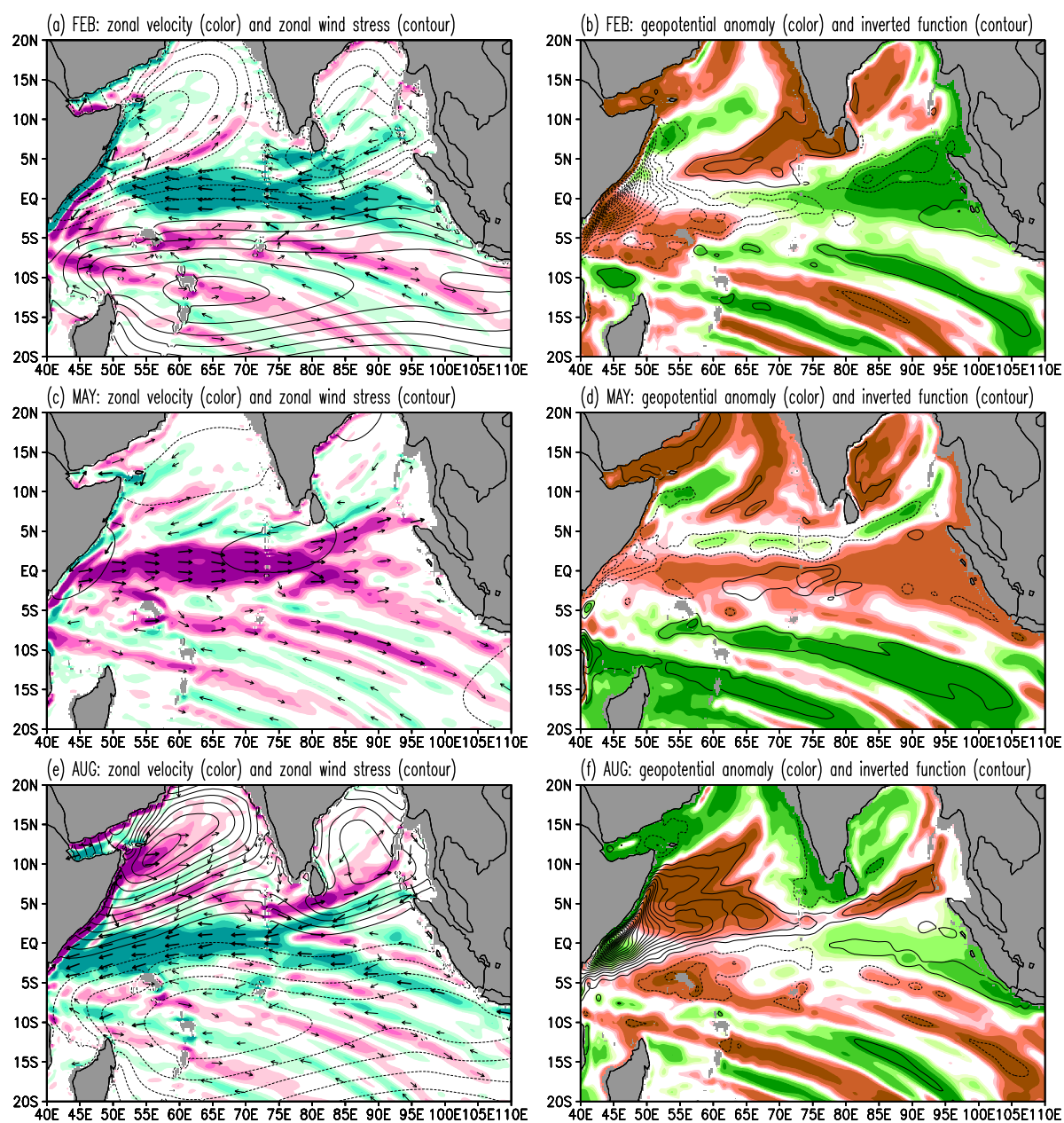

20S 45E 50E 55E 60E 65E 70E 75E 80E 85E 90E 95E 100E105E 110E
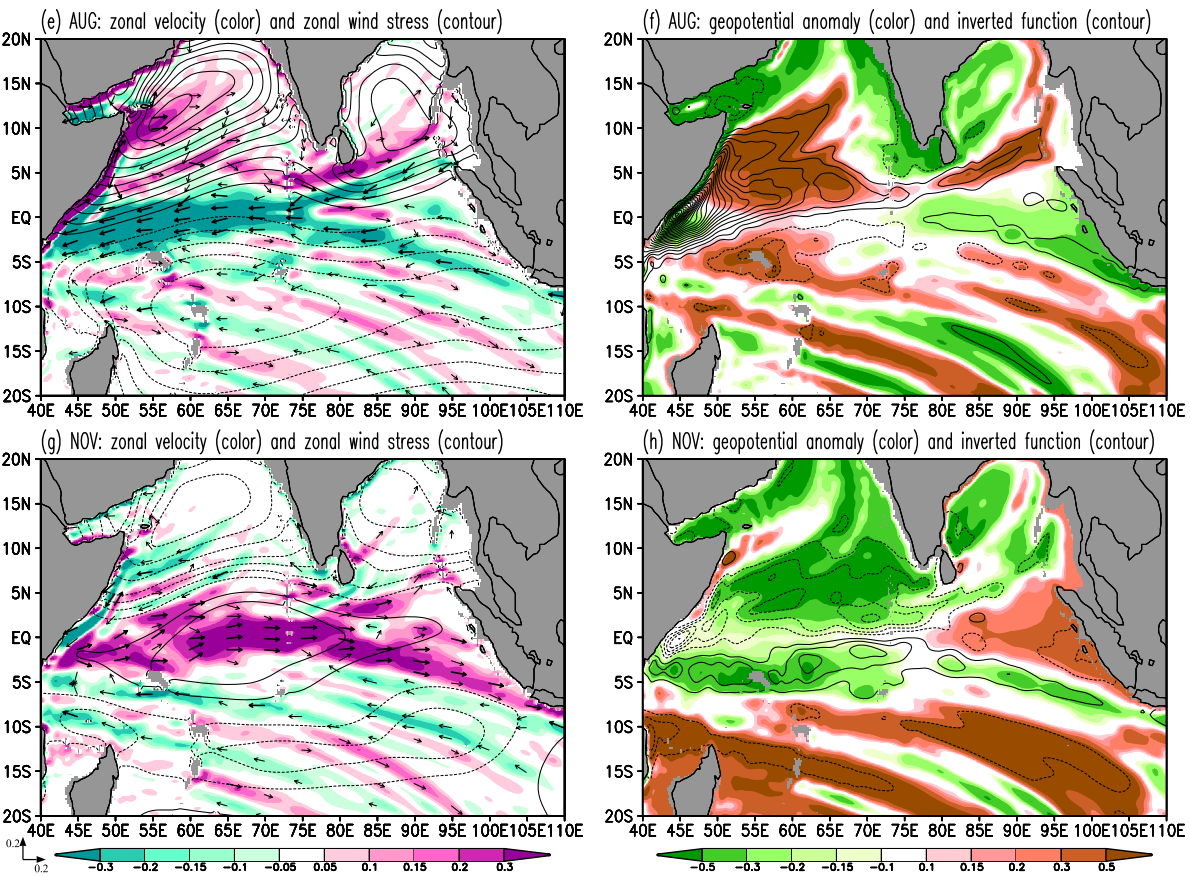

Fig. 1 Left panels: the zonal component of simulated velocity at the sea surface (color shading with a unit of $\mathrm{m} / \mathrm{s}$ ), the zonal component of wind stress in the model (solid and dotted contours for eastward and westward anomalies, respectively, with an interval of $0.02 \mathrm{~N} / \mathrm{m}^{2}$ ), and the velocity vector (arrows in units of $\mathrm{m} / \mathrm{s}$ ) in the middle of a February, c May, e August, and $\mathbf{g}$ November from "Year 20 " of our climatological model experiments. When under $0.2 \mathrm{~m} / \mathrm{s}$, the

magnitude of simulated velocity vectors in left panels is indicated either by arrow length or, for greater values, by heavy arrows of uniform length. Right panels $\left(\mathbf{b}, \mathbf{d}, \mathbf{f}\right.$, and $\mathbf{h}$ ): same as left panels except for simulated sea surface geopotential anomaly (color shading with a unit of $\mathrm{m}^{2} / \mathrm{s}^{2}$ ) and PV-inverted function at the sea surface (solid and dotted contours represent positive and negative values, respectively, with an interval of $20,000 \mathrm{~m}^{2} / \mathrm{s}$ ). The PV-inverted function may be interpreted as geostrophic streamfunction in off-equatorial regions. The sea surface quantities have been reconstructed from the model results of fundamental six baroclinic modes (Appendix)

downwelling (during the monsoon transition period) KWs. The propagation of waves has a deterministic role on the vertical profile of geopotential anomalies (see Figure S1 in Supplementary Material). The semiannual signals of geopotential anomalies are weaker than that of zonal velocity, which are attributed to the interaction between KWs and RWs in the central Indian Ocean (Yuan and Han 2006). The upward phase signals of both zonal velocity and geopotential 

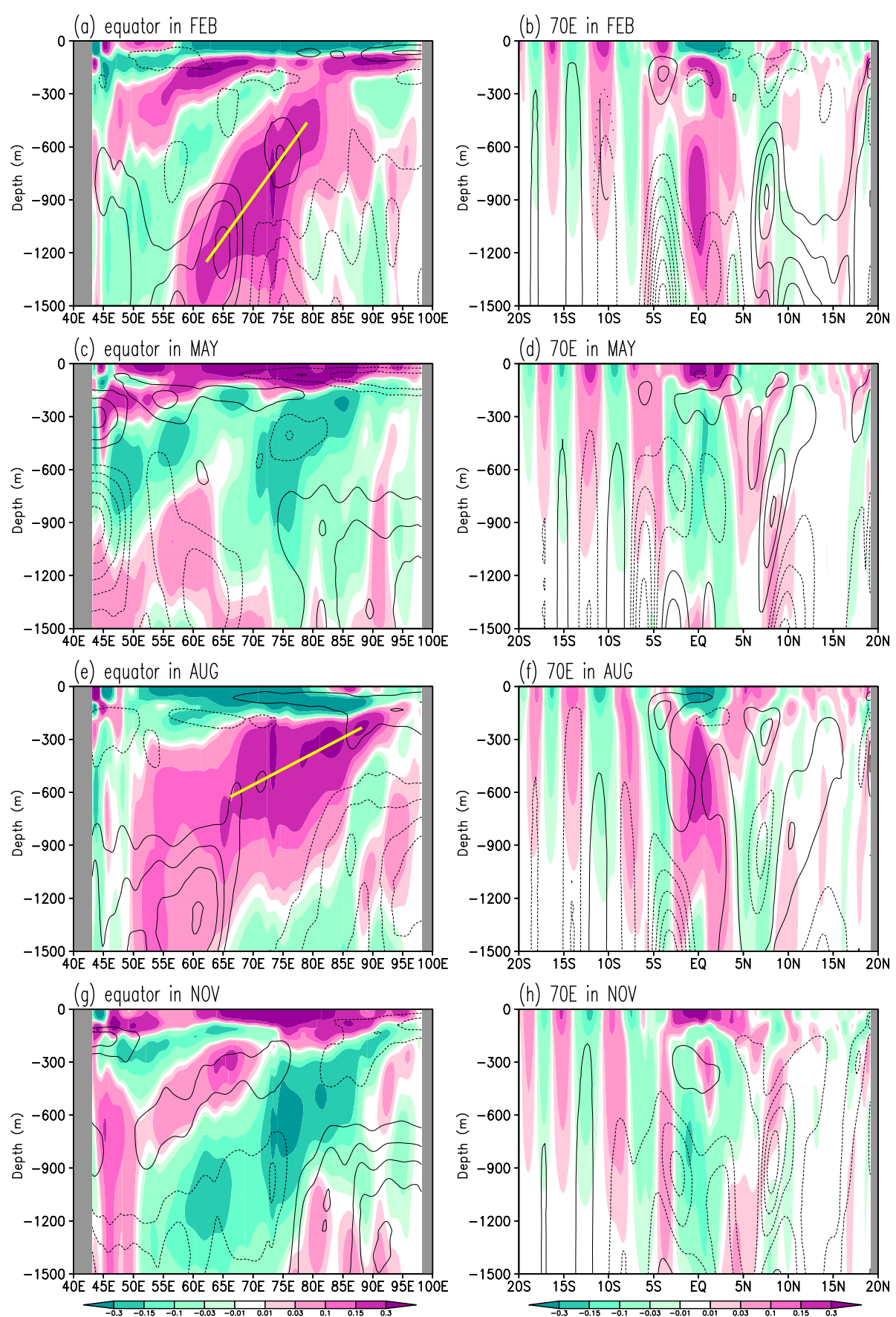

Fig. 2 The zonal component of simulated velocity (color shading with a unit of $\mathrm{m} / \mathrm{s}$ ) and the vertical component of simulated velocity (solid-and dotted-contours indicate positive and negative values, respectively, with an interval of $4 \times 10^{-6} \mathrm{~m} / \mathrm{s}$ ) shown by snapshots in the middle of $\mathbf{a}$, $\mathbf{b}$ February, c, d May, e, f August, and $\mathbf{g}$, h November from "Year 20" of our climatological model experiments. Zonal-vertical section at the equator (left panels) and meridional-vertical section at $70^{\circ} \mathrm{E}$ (right panels)

anomaly shift gradually in depth, and variability in the deeper layer leads to that in the upper layer. This is regarded as the indication of downward energy transfers by oceanic waves (McCreary 1984; Miyama et al. 2006; Pujiana and McPhaden 2020).

\section{Results and discussions}

This paper presents results from the first oceanic application of the depth-dependent version of the AGC17 scheme. In the following, all results associated with the AGC17 scheme were obtained using this extended 


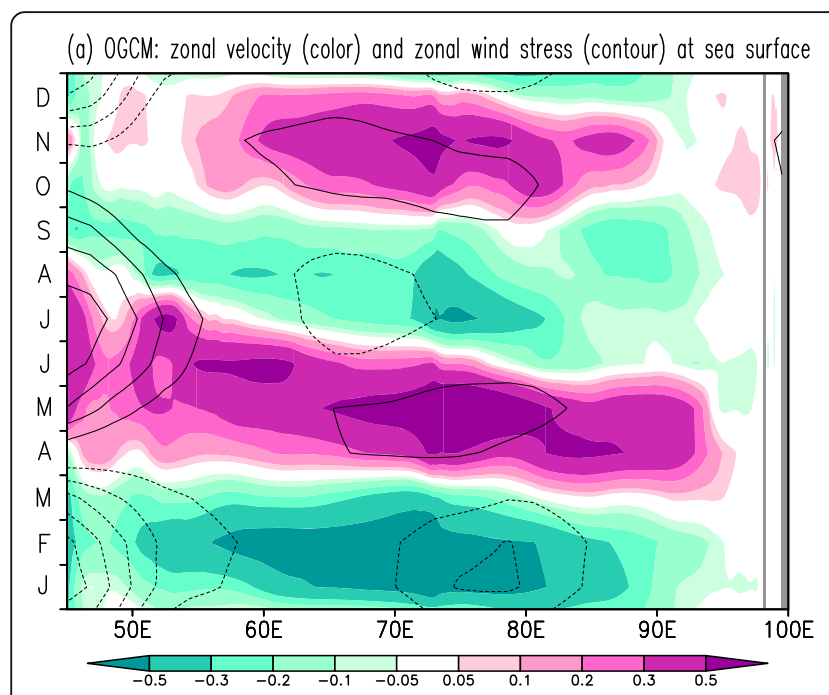

(c) LOM: zonal velocity (color) and zonal wind stress (contour) at sea surface
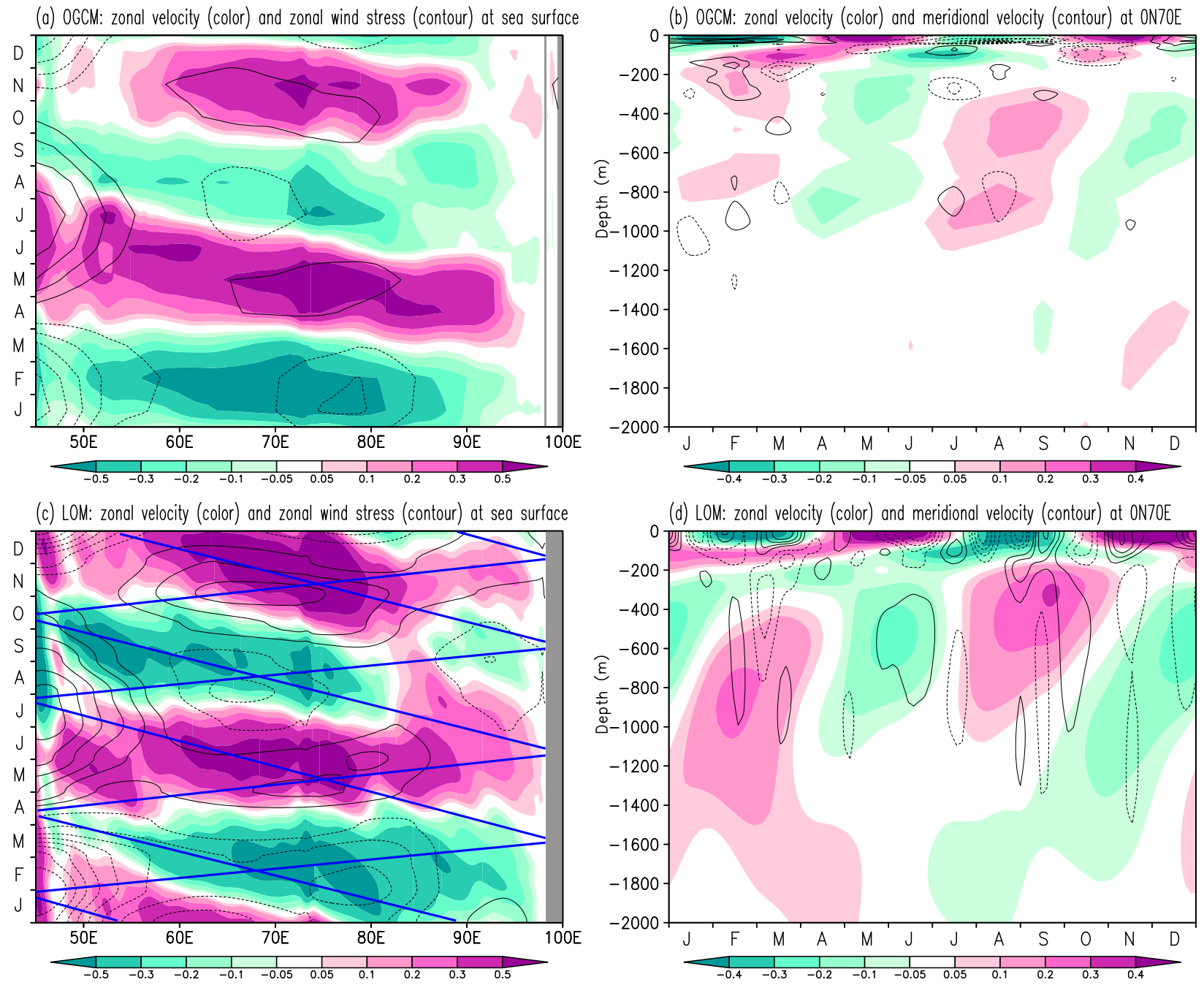

(e) LOM: geopotential anomaly at sea surface

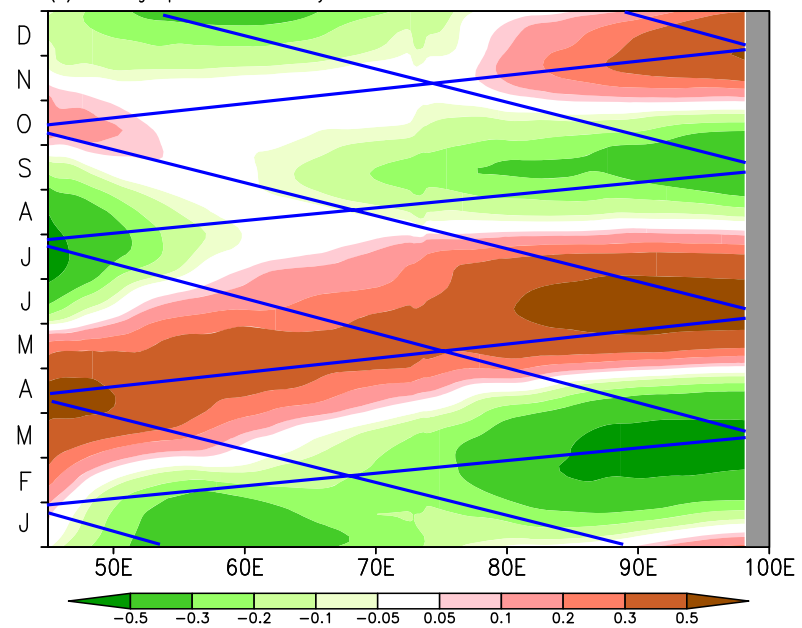

(f) LOM: geopotential anomaly (color) and vertical velocity (contour) at ON7OE

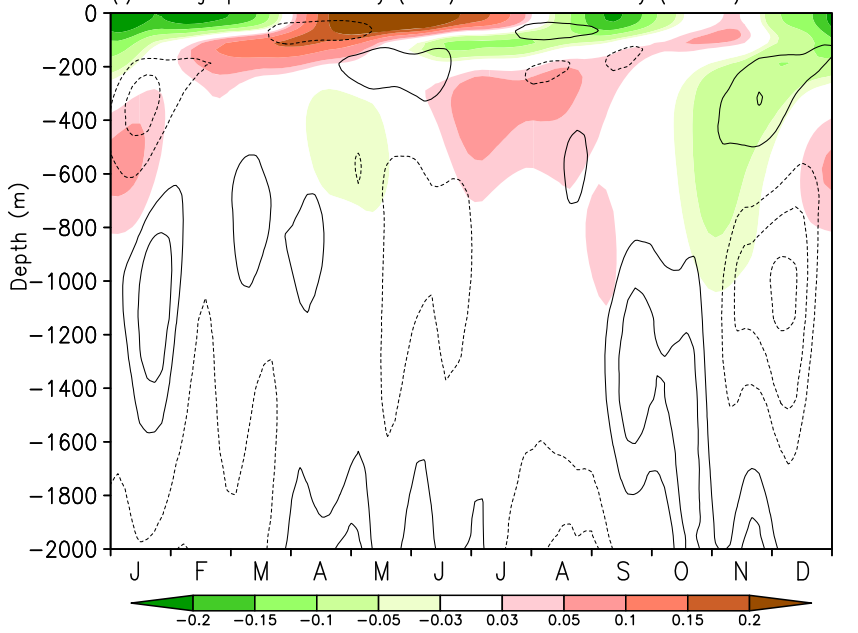

Fig. 3 (See legend on next page.) 
(See figure on previous page.)

Fig. 3 Hovmöller zonal-time diagrams at the sea surface of the equator (left panels) and depth-time diagrams at $70^{\circ} E$ of the equator (right panels) from OGCM OFES (a, b) and "Year 20" of our climatological model experiments ( $\mathbf{c}-\mathbf{f}$ ), respectively. Color shading in the panels (a-d) shows the output of zonal component of velocity based on OGCM $(\mathbf{a}, \mathbf{b})$ and $\operatorname{LOM}(\mathbf{c}, \mathbf{d})$ with a unit of $\mathrm{m} / \mathrm{s}$. Color shading in the panels $(\mathbf{e}-\mathbf{f})$ shows simulated geopotential anomaly with a unit of $\mathrm{m}^{2} / \mathrm{s}^{2}$. Panels $(\mathbf{a}, \mathbf{c})$ include the zonal component of wind stress (solid and dotted contours for positive and negative values, respectively, with an interval of $0.1 \mathrm{~N} / \mathrm{m}^{2}$ ) from OGCM and LOM, respectively. Panels $(\mathbf{b}$, $\mathbf{d}$ ) include the meridional component of velocity based on OGCM and LOM (solid- and dotted-line contours for positive and negative values, respectively, with an interval of $0.02 \mathrm{~m} / \mathrm{s}$ ). Panel (f) includes the vertical component of simulated velocity (solid and dotted contours for positive and negative values, respectively, with an interval of $4 \times 10^{-6} \mathrm{~m} / \mathrm{s}$ ). Solid blue lines in the panels (c, e) indicate the theoretical phase speeds of both Kelvin waves and equatorial long Rossby waves in the second baroclinic mode

version. We use the pressure flux (hereafter PF) scheme, as given by $\rho_{0} \overline{\mathrm{U} \Phi}$, for comparison with the AGC17 scheme, which is identical to flux defined by Eq. (3b) except for $\rho_{0}$. While the PF scheme yields meridionally alternating energy flux vectors (Fig. 4a), the AGC17 scheme is able to show basin-wide cyclonic patterns, which represent the depth-integrated transfer routes of KW and RW energy (Fig. 4b). These waves are driven by wind energy input in the vicinity of the Maldives (from $60^{\circ} \mathrm{E}$ to $80^{\circ} \mathrm{E}$ ), the Arabian Sea and the southern Bay of Bengal (SBoB), as shown by the positive values of energy-flux potential (indicated by the contours of Fig. 4b). Near the African coasts, energy flux streamfunction derived from the AGC17 scheme (color shadings in Fig. $4 \mathrm{~b})$ reveals cyclonic circulation that is localized in nature, whereas on the east side of the basin, the cyclonic circulation develops on significantly larger spatial scales in each hemisphere, as identified by LA20.

In terms of model performance at the key depths of 550 $\mathrm{m}$ and $1100 \mathrm{~m}$, the PF scheme fails to reveal important energy fluxes with distinct eastward KW signatures and similarly misses a series of westward signals associated with midlatitude RWs (Fig. 4c, e). In contrast, the AGC17 scheme is able to show the eastward transfer of wave energy along the equator associated with equatorial KWs and also the westward transfer of wave energy in offequatorial regions associated with midlatitude RWs (Fig. $4 \mathrm{~d}, \mathrm{f})$. Note that pressure variability along the equator represents KWs and zonal velocity variability along the equator are caused by RWs (Yu and McPhaden 1999; Ding et al. 2009; Nagura and McPhaden 2010a, b). The AGC17 scheme is appropriate when tracking the group velocity of baroclinic waves at all latitudes, particularly as it incorporates a realistic smooth transitioning between the tropical and subtropical regions. The contours in Fig. $4 \mathrm{~d}$ and $\mathrm{f}$ show the vertical component of energy flux. Note that downward energy propagation is large in magnitude in the SBoB, the south Arabian Sea and the region between the equator and $5^{\circ} \mathrm{S}$ in $55^{\circ}-75^{\circ} \mathrm{E}$. In particular, the downward transfer of wave energy reaches its greatest depth in $\mathrm{SBoB}$, as is described below.

Along the latitude-depth plane at $70^{\circ} \mathrm{E}$, the westward flux of RW energy is symmetrically distributed across the equator (color shading in Fig. 5a). The vertical flux of wave energy at $90^{\circ} \mathrm{E}$ (contours in Fig. $5 \mathrm{~b}$ ) reaches a deep level at around $3^{\circ}-5^{\circ} \mathrm{N}$, corresponding to the downward flux of RW energy in the SBoB (Fig. 4d, f). The characteristics of this downward flux ${ }^{1}$ are investigated by comparing time-depth diagrams at $70^{\circ} \mathrm{E}$ and $90^{\circ} \mathrm{E}$ along $3^{\circ} \mathrm{N}$ (Fig. 5c, d). The zonal component of energy flux based on the AGC17 scheme shows negative peaks four times per year, which is more distinct at $90^{\circ}$ $\mathrm{E}$ than at $70^{\circ} \mathrm{E}$ (color shadings in Fig. 5c, d). The vertical component of energy flux at $90^{\circ} \mathrm{E}$ (contours in Fig. 5d) also shows negative peaks four times per year that become deepest in November-December. These features can be generated by either wind forcing in the SBoB or by the reflection and diffraction of equatorial KWs as they encounter the eastern boundary, as will be discussed in the next paragraph. The time-depth diagrams of the energy flux at $70^{\circ} \mathrm{E}$ and $90^{\circ} \mathrm{E}$ on the equator (Fig. $5 \mathrm{e}, \mathrm{f})$ show peaks of eastward energy flux when zonal velocity exhibits upward phase propagation (Fig. 3d).

The Hovmöller longitude-time plots at the equator (panels on the left in Fig. 6) and at $3^{\circ} \mathrm{N}$ (panels on the right) shows zonal energy flux derived from the AGC17 scheme (color shadings). Zonal energy flux along the equator shows four beams per year at both the surface and at $550 \mathrm{~m}$ depth, which suggests a group velocity consistent with the second baroclinic mode KWs (blue solid lines). In contrast, the westward transfers of wave energy at the equator and at $3^{\circ} \mathrm{N}$ indicate group velocities consistent with both reflected equatorial RWs and diffracted midlatitude RWs. The surface eastward flux along the equator, which is intense in both February and May, is associated with upwelling and downwelling KWs, respectively (Fig. 6a). Energy input rate by wind forcing (Fig. 7) is predominant along the African coast during the northeast monsoon and southwest monsoon than that of during boreal spring and fall. Monsoonal winds excite the upwelling KWs along the African coast and bring the divergence towards the equator. It is

\footnotetext{
${ }^{1}$ The vertical energy flux at $103^{\circ} \mathrm{E}, 6^{\circ} \mathrm{S}$ shows a similar deepest reaching pattern in November-December (not shown), which indicates that the reflection and diffraction of equatorial KWs affect both Northern and Southern Hemispheres.
} 


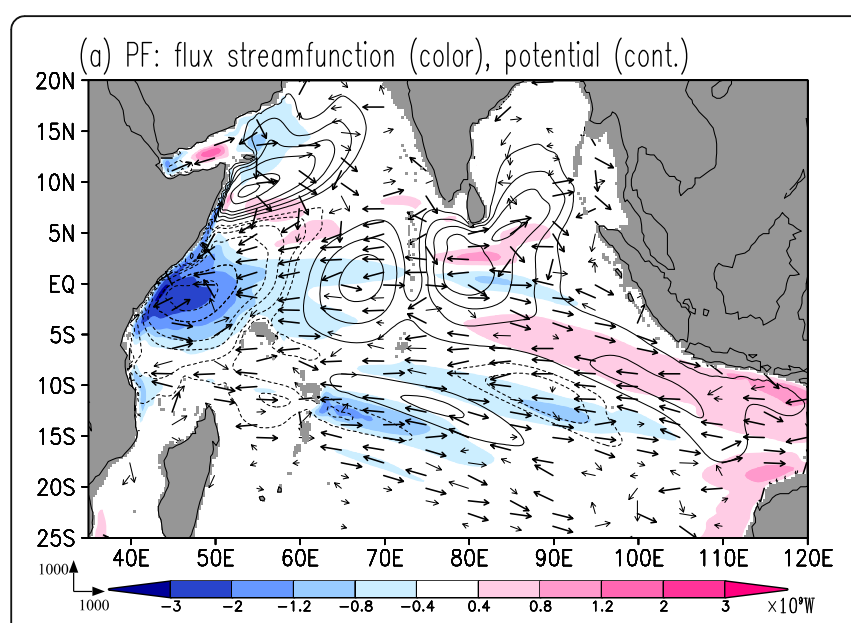

(b) AGC: flux streamfunction (color), potential (cont.)

(c) PF at $z=-550 \mathrm{~m}$ : zonal flux (color)
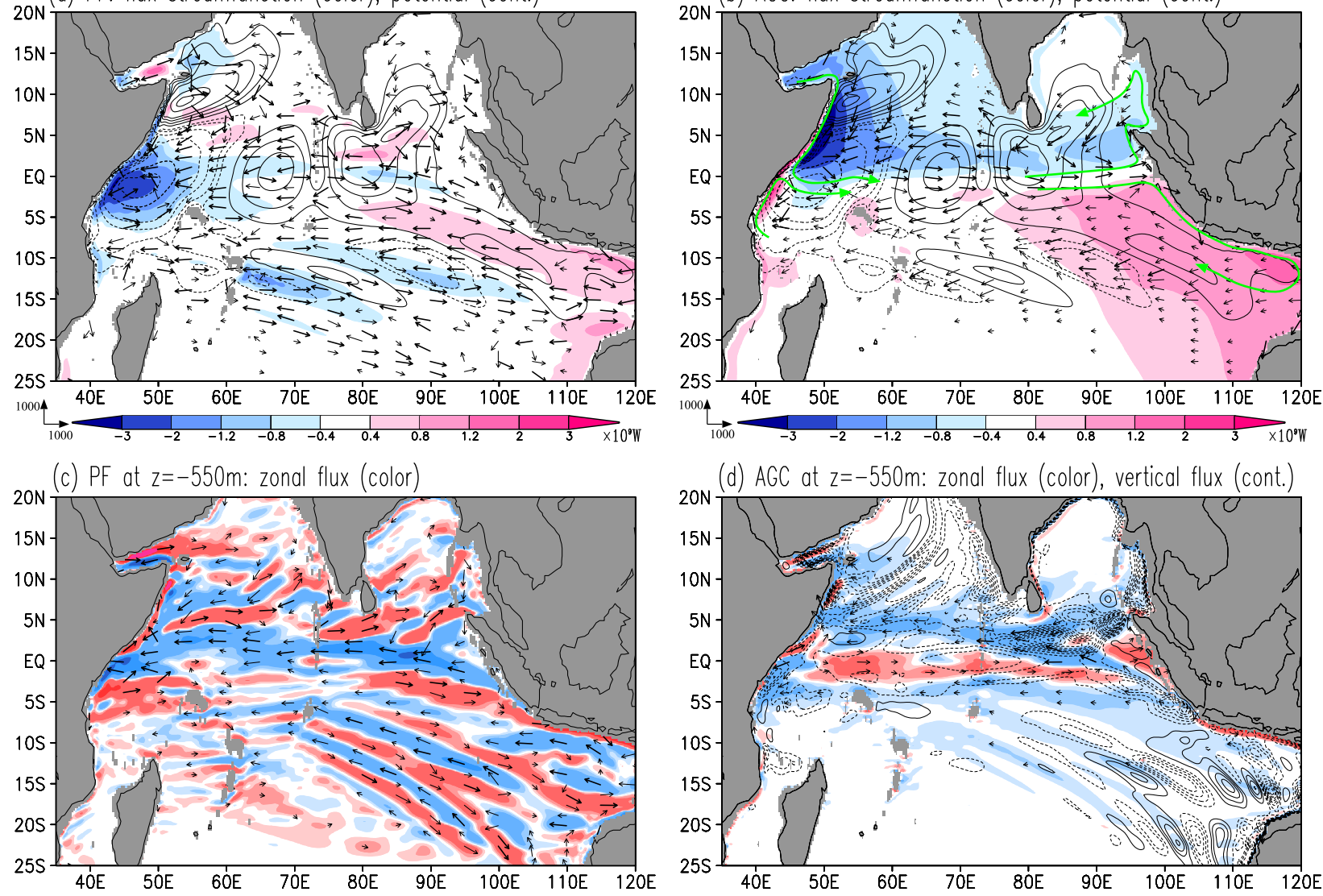

(d) ACC at $z=-550 \mathrm{~m}$ : zonal flux (color), vertical flux (cont.)

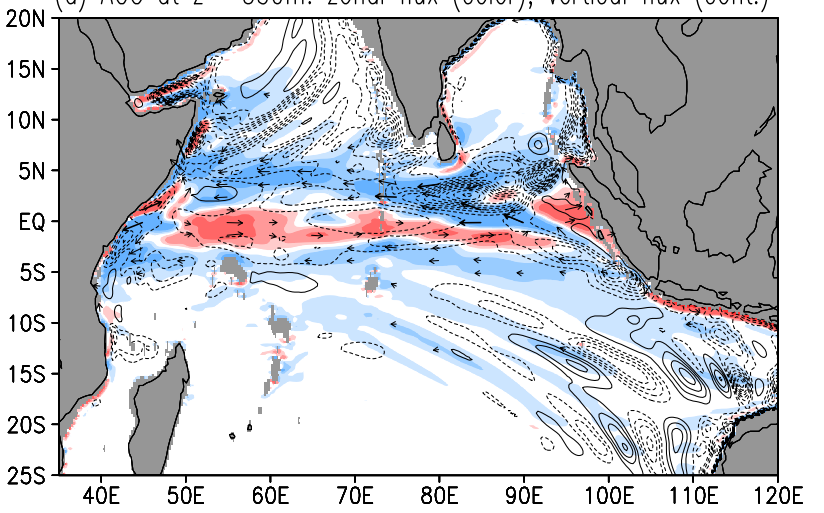

(e) PF at $z=-1100 \mathrm{~m}$ : zonal flux (color)
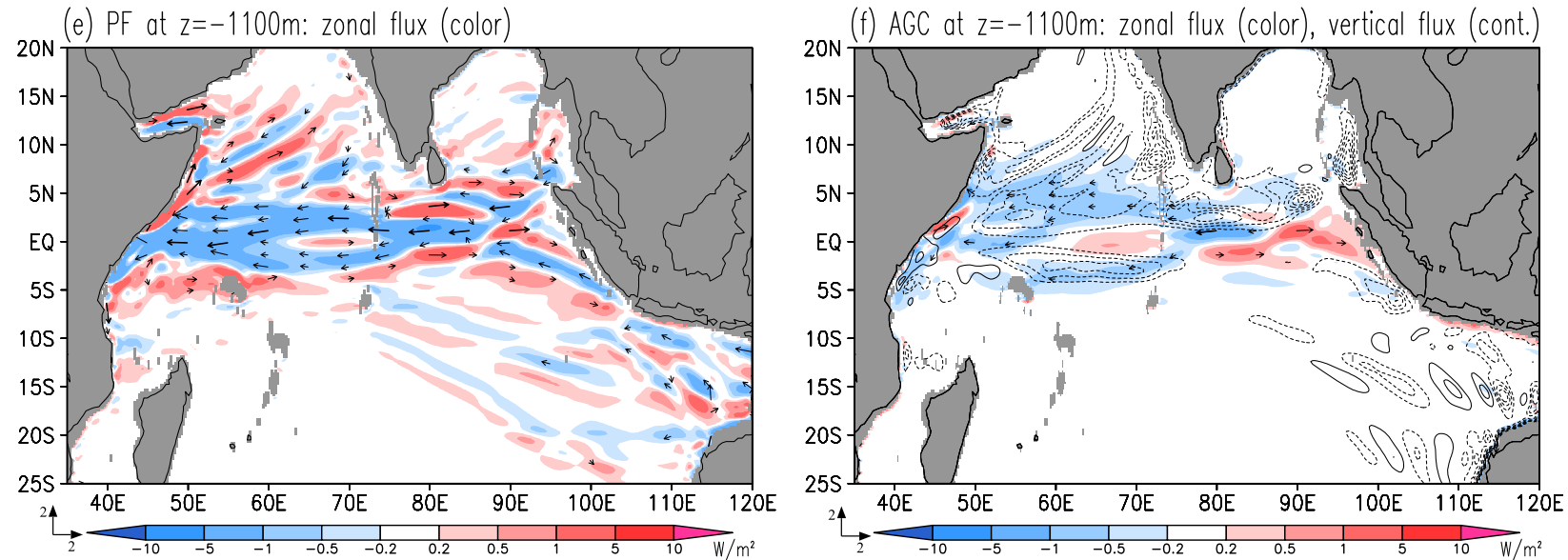

Fig. 4 a, b Depth-integrated energy flux streamfunctions (color shaded in units of $10^{9} \mathrm{~W}=\mathrm{GW}$ ), depth-integrated energy flux potentials (solid contours for positive values and dotted contours for negative values; contour interval $=0.05 \mathrm{GW}$ ), and depth-integrated energy flux vectors (arrows in units of $\mathrm{W} / \mathrm{m}$ ). $\mathbf{c}$, $\mathbf{d}$ The zonal component of the energy flux (color shaded in units of $\mathrm{W} / \mathrm{m}^{2}$ ) and the energy flux vector (arrows in units of $\mathrm{W} / \mathrm{m}^{2}$ ) at $550 \mathrm{~m}$ depth. e, $\mathbf{f}$ Same as $\mathbf{c}$ and $\mathbf{d}$ except that depth is now $1100 \mathrm{~m}$. All quantities represent annual mean values taken from "Year 20" of the model experiments, and estimated by the pressure flux scheme (left panels) and the depth-dependent version of the Aiki, Greatbatch, and Claus Level-2 scheme (right panels). Panel (b) includes two groups of cyclonic circulations of wave energy shown by green arrows that are demonstrated in LA20. Panels ( $\mathbf{d}$ and $\mathbf{f}$ ) include the vertical component of the energy flux, shown by contours (solid for positive and dotted for negative values) at an interval of $10^{-4} \mathrm{~W} / \mathrm{m}^{2}$. When under $1000 \mathrm{~W} / \mathrm{m}$, the magnitude of the depth-integrated energy flux vectors in $(\mathbf{a}, \mathbf{b})$ is indicated either by arrow length or, for greater values, by heavy arrows of uniform length. Arrows in the series $\mathbf{c}, \mathbf{d}, \mathbf{e}$, and $\mathbf{f}$ are displayed in a similar fashion to $(\mathbf{a})$ and $(\mathbf{b})$, with the magnitude of the energy flux indicated either by arrow length (when under $2 \mathrm{~W} / \mathrm{m}^{2}$ ) or by heavy arrows of uniform length for greater values 


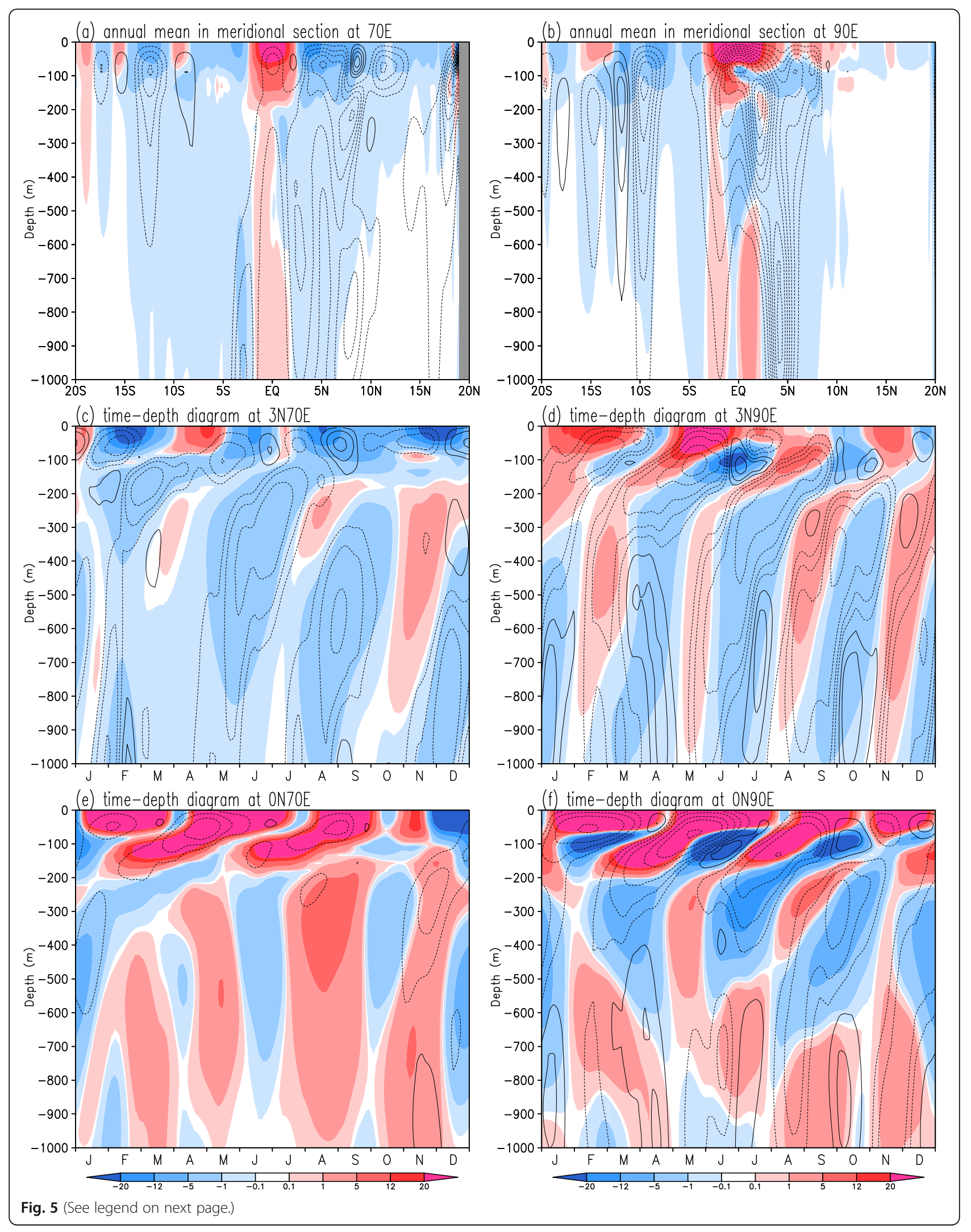


(See figure on previous page.)

Fig. 5 The zonal component of the energy flux (color shaded in units of $\mathrm{W} / \mathrm{m}^{2}$ ) and the vertical component of the energy flux (solid contours for positive values and dotted contours for negative values $(\mathbf{a}, \mathbf{b})$ with an interval of $10^{-4} \mathrm{~W} / \mathrm{m}^{2}$, (c- $\left.\mathbf{f}\right)$ at magnitude levels of 2, 5, 10, 20, 30, 50 $\times 10^{-4} \mathrm{~W} / \mathrm{m}^{2}$ ) as estimated from the depth-dependent version of the Aiki, Greatbatch, and Claus Level-2 scheme, as given by (7b). Annual means in the meridional-vertical sections are shown in $\mathbf{a}$ at $70^{\circ} \mathrm{E}$ and $\mathbf{b}$ at $90^{\circ} \mathrm{E}$. Hovmöller time-depth diagrams at $3^{\circ} \mathrm{N}$ for $\mathbf{c} 70^{\circ} \mathrm{E}$ and $\mathbf{d} 90^{\circ} \mathrm{E}$ and on the equator for $\mathbf{e} 70^{\circ} \mathrm{E}$ and $\mathbf{f} 90^{\circ} \mathrm{E}$. All quantities are derived from "Year $20^{\prime \prime}$ of the climatological model experiments associated with first six

fundamental baroclinic modes

consistent with the remarkable energy input by wind forcing at the African coast during boreal winter and summer at the equator and $3^{\circ} \mathrm{N}$ at the surface. In contrast, the eastward flux at $550 \mathrm{~m}$ depth along the equator is intense in both May and August (Fig. 6c) and reaches $1100 \mathrm{~m}$ depth in November (Fig. 6e), as shown by the time-depth diagram of Fig. 5e.

The poleward diffraction of equatorial KWs at the eastern boundary of the IO, followed by the radiation of off-equatorial RWs four times per year, is clearer at 550 $m$ depth (Fig. 6d) than at the surface (Fig. 6b). This is because energy fluxes at the surface are forced by winds (contours in Fig. 6a, b) and represent the superposition of forced and freely propagating waves. Energy input by winds is more significant at $3^{\circ} \mathrm{N}$ than at the equator, which may be confirmed by the distribution of energy flux potential (contours in Fig. 4b). Returning to the issue of the SBoB downward energy flux that peaks in November-December, we note that energy input by winds peaks in February and June between 80 and $90^{\circ} \mathrm{E}$ (Fig. 6b). It is less likely that wind forcing is the primary factor to generate SBoB downward flux in NovemberDecember. We note that the SBoB downward flux is induced by the boundary diffraction of mid-depth equatorial KW beam which peaks in August (Fig. 6c). As explained in the previous paragraph, eastward energy fluxes along the equator at $550 \mathrm{~m}$ depth lag behind those at the surface by 3 months.

This is further investigated using snapshots of energy fluxes in the longitude-depth sections along the equator (Fig. 8, left) and along $3^{\circ} \mathrm{N}$ (Fig. 8, right). Zonal energy flux at the equator propagates eastward at depths between 300 and $1000 \mathrm{~m}$ in August (colours in Fig. 8e). This eastward peak in the western basin is followed by the development of an eastward energy flux in the central basin at around $900 \mathrm{~m}$ depth in November (Fig. 8g). These results indicate that the southwest monsoon over the African coast directly causes the August maximum in eastward energy flux at $550 \mathrm{~m}$ depth in Fig. 6c. Southwesterly winds over the Arabian Sea drive a strong northward East African Coastal Current along the continental coasts. The current crosses the equator and is accelerated by winds in July, while the divergence of the surface flow excites upwelling KWs along the equator. The eastward transfer of KW energy is amplified by the southwest monsoon and appears not only at the sea surface but also at mid-depth. The boundary-diffracted RWs associated with these equatorial KWs dominate the downward penetration of wave energy in the SBoB, with signals reaching the greatest depths in November-December. Contours in Fig. 8 show the vertical component of energy flux. At $3^{\circ} \mathrm{N}$ (right panels), energy flux is downward all the year and represents an intense westward energy flux associated with off-equatorial RWs around $75-90^{\circ}$ E. Both westward and downward energy fluxes reach greatest depths in November (Fig. 8h). The above results highlight propagation and reflection of oceanic waves and clearly determine their origins. Thus the depth-dependent version of the AGC17 scheme is able to reveal the properties of waves at subsurface and provides a better understanding of the processes governing the transfer of wave energy.

\section{Conclusions}

In order to study the effect of annual and semiannual wind forcing on wave propagations in mid-depth in the tropical IO, we have estimated wave energy flux using output from a linear model driven by climatological wind forcing. We have compared the performance of the $\mathrm{PF}$ scheme to that of the depth-dependent version of the AGC17 scheme summarized herein. The PF scheme represents meridionally alternating signals through the basin at the surface and shows neither eastward KW energy flux along the equator nor the westward transfer of energy flux related to off-equatorial RWs. The AGC17 scheme provides a better treatment of energy flux of both equatorial KWs and RWs and smoothly links the tropical and subtropical regimes.

Eastward energy flux shows distinct semiannual variations along the equator at subsurface, peaking four times per year, which indicate that energy given by surface monsoonal winds reaches below the pycnocline. The eastward flux at the surface on the equator is intense in both February and May associated with upwelling and downwelling KWs forced by semiannual winds, respectively. Eastward flux at $550 \mathrm{~m}$ depth at the equator is intense in both May and August and reaches down to $1100 \mathrm{~m}$ depth in November. In off-equatorial regions, westward energy flux associated with RWs exhibits four clearly defined peaks.

The SBoB is the region where wave energy penetrates deepest. This downward energy flux is clearest at around 


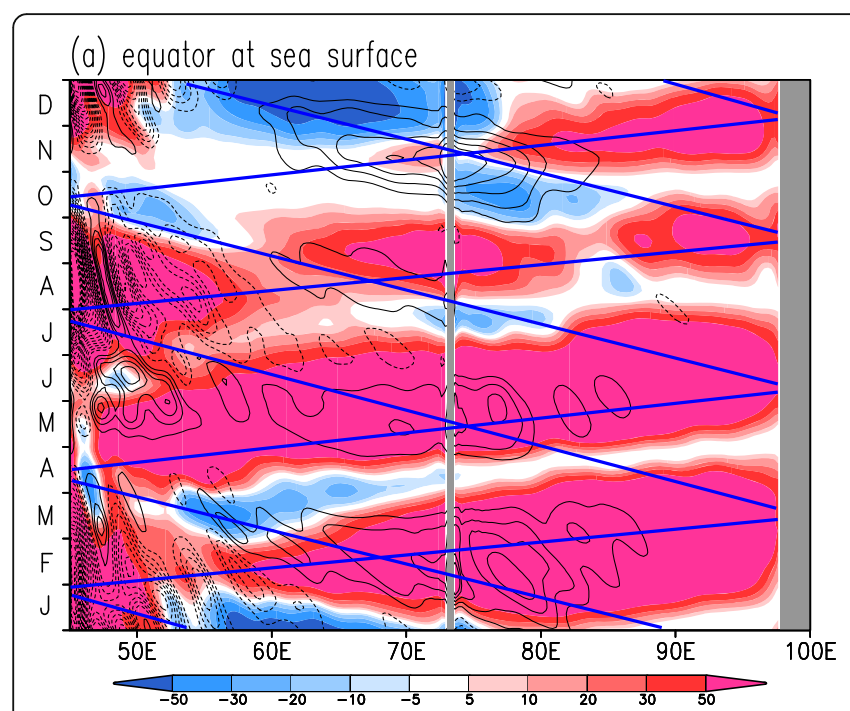

(b) $3 \mathrm{~N}$ at sea surface

(c) equator at $z=-550 \mathrm{~m}$
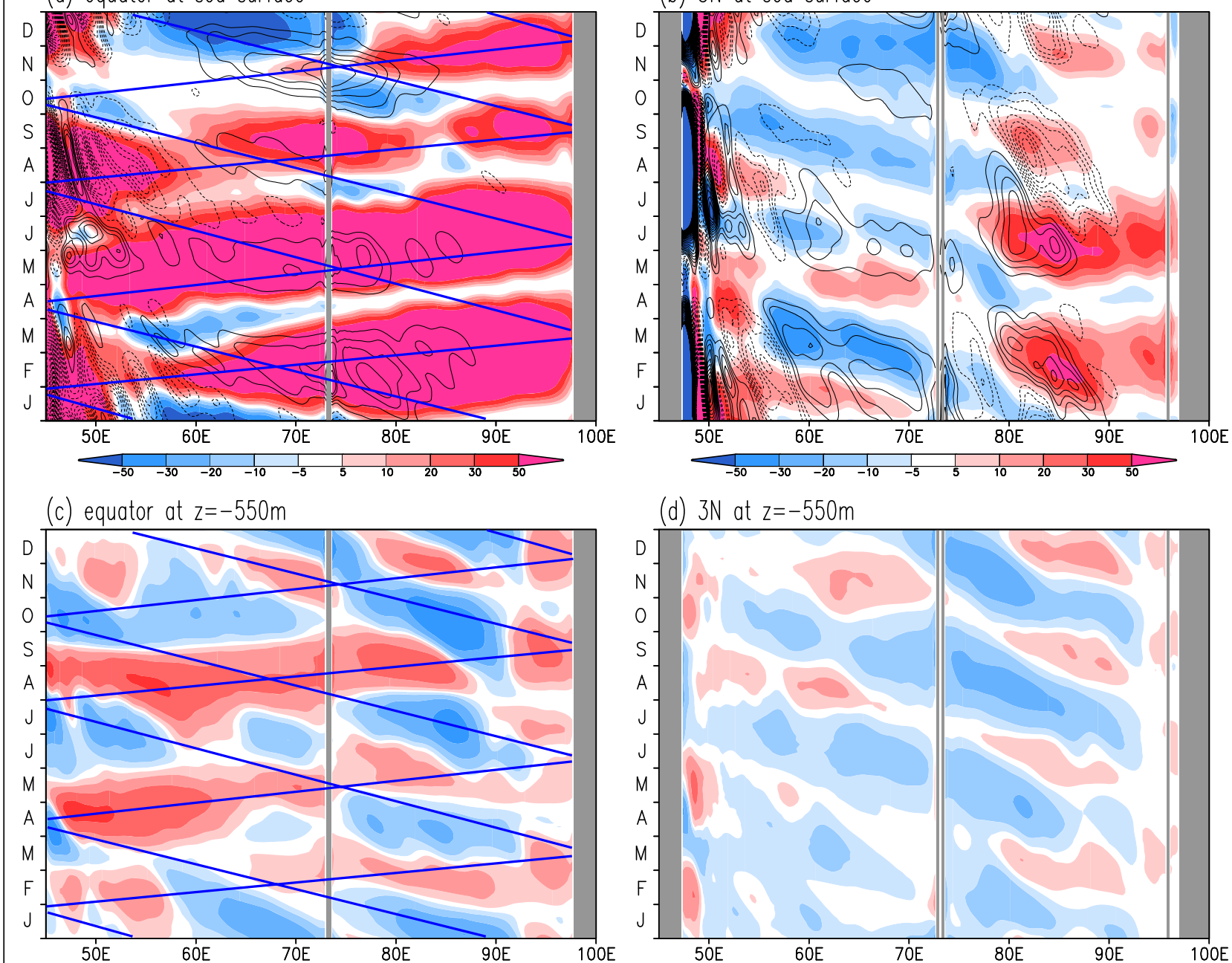

(d) $3 \mathrm{~N}$ at $\mathrm{z}=-550 \mathrm{~m}$

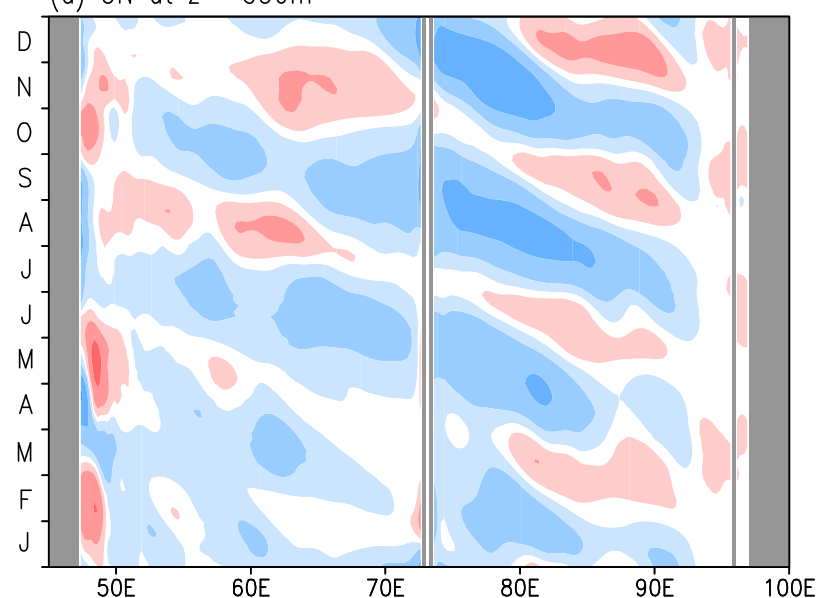

(e) equator at $z=-1100 m$

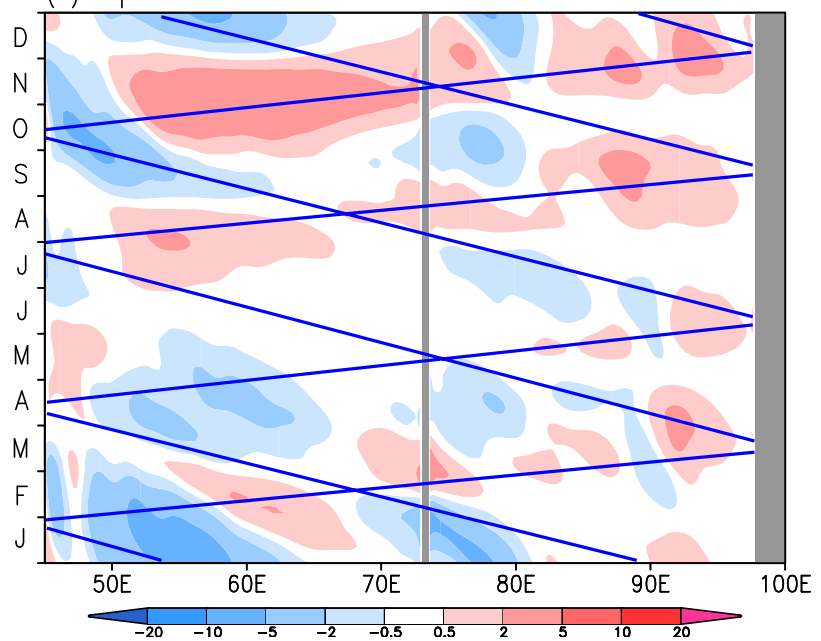

(f) $3 \mathrm{~N}$ at $\mathrm{z}=-1100 \mathrm{~m}$

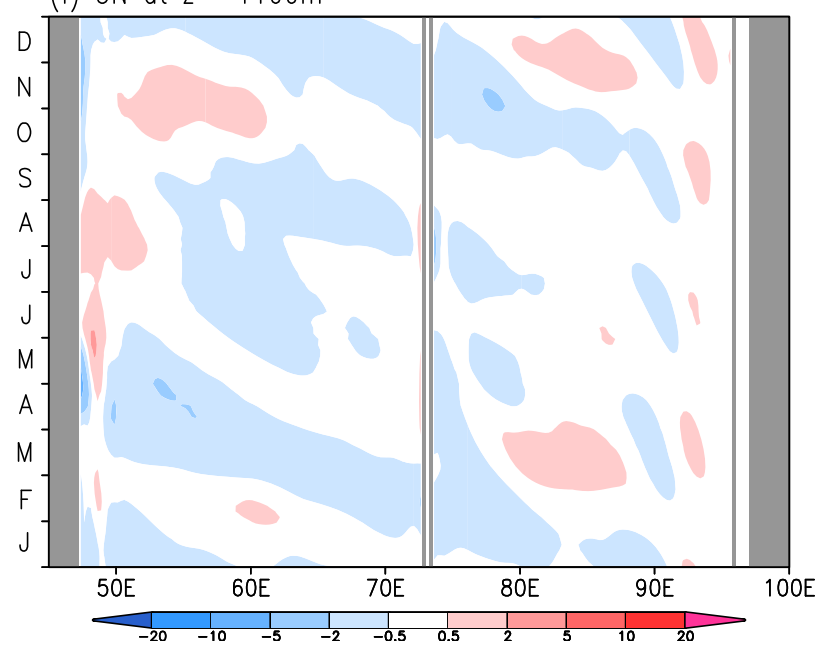

Fig. 6 (See legend on next page.) 
(See figure on previous page.)

Fig. 6 Hovmöller zonal-time diagrams for the zonal component of energy flux (color shaded in units of W/m²) at $\mathbf{a}$, b sea surface, c, d $550 \mathrm{~m}$ depth, and e, f $1100 \mathrm{~m}$ depth. Left panels show the equatorial behavior, while right panels are for $3^{\circ} \mathrm{N}$. Energy flux has been estimated using the depth-dependent version of the Aiki, Greatbatch, and Claus Level-2 scheme, as given by (7b). Panels (a, $\mathbf{b})$ include wind-forced wave energy input (solid contours for positive values, dotted contours for negative values; contour interval $=0.002 \mathrm{~W} / \mathrm{m}^{2}$ ) following (12). All quantities are from "Year 20" of the model experiments associated with first six fundamental baroclinic modes. In the left-hand panels, theoretical phase speeds calculated for both Kelvin waves and equatorial long Rossby waves are shown as solid blue lines

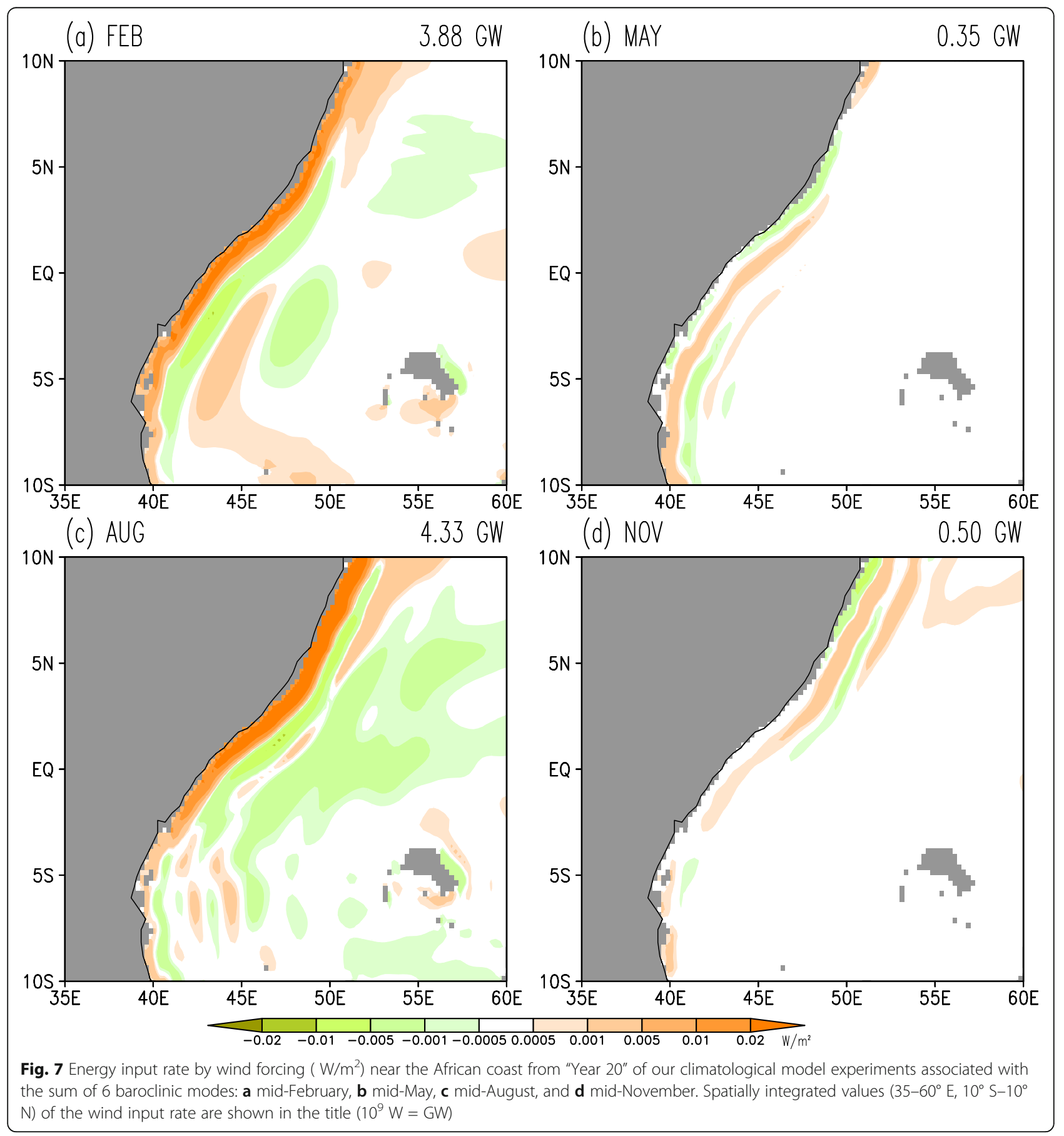



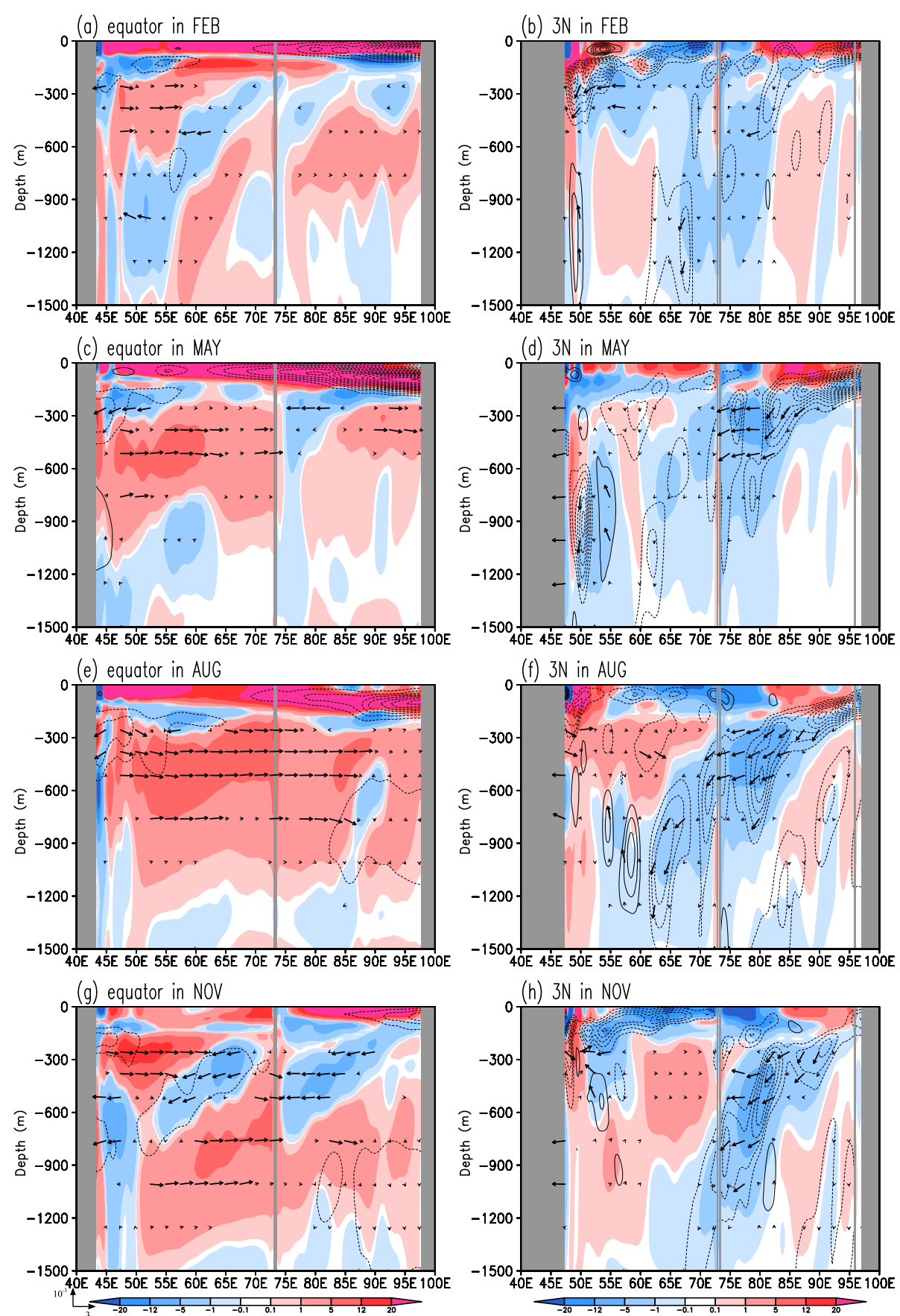

Fig. 8 Zonal-vertical sections at the equator (left) and at $3^{\circ} \mathrm{N}$ (right) from "Year 20" of our climatological model experiments: a, b mid-February, $\mathbf{c}$, $\mathbf{d}$ mid-May, e, $\mathbf{f}$ mid-August, and $\mathbf{g}, \mathbf{h}$ mid-November. The zonal component of the energy flux (color shaded in units of W/m²), the vertical component of the energy flux (solid contours for positive values, dotted contours for negative values; with an interval of $4 \times 10^{-4} \mathrm{~W} / \mathrm{m}^{2}$ ) and the energy flux vector (arrows in units of $\mathrm{W} / \mathrm{m}^{2}$ ) estimated from the depth-dependent version of the Aiki, Greatbatch, and Claus Level-2 scheme, as given by (7b). When under $3 \mathrm{~W} / \mathrm{m}^{2}$, the magnitude of energy flux is indicated either by arrow length or, for greater values, by heavy arrows of uniform length

$3-5^{\circ} \mathrm{N}, 90^{\circ} \mathrm{E}$ that we attributed to the downward flux of RW energy. The energy input due to wind forcing at $3^{\circ}$ $\mathrm{N}$ peaks between 80 and $90^{\circ} \mathrm{E}$ in February and June and cannot account for downward energy flux in
November-December. An alternative explanation is that the boundary diffraction of mid-depth equatorial KWs is responsible for the downward penetration of energy in the SBoB. The AGC17 scheme has shown that eastward 
energy flux at $550 \mathrm{~m}$ depth at the equator peaks in August, which induces boundary-diffracted RWs at this depth at $3^{\circ} \mathrm{N}$ in November-December. The peak in August may in part be due to the maximum of eastward energy flux in May at the surface on the equator. The maximum mid-depth eastward flux lags behind that of the surface eastward flux by 3 months, suggesting a downward propagation of wave energy.

A further important contribution is made by winds of the southwest monsoon in the Arabian Sea, which generates the divergence of energy at the surface near the equator along the African coastline and excites upwelling equatorial KWs in July. This process can have a direct impact on the formation of the peak in eastward energy flux associated with KWs in August below $300 \mathrm{~m}$ depth. These equatorial KW packets are diffracted poleward along the eastern boundary and become the source of off-equatorial RWs. The latter is responsible for the downward flux of wave energy which reaches the greatest depth in November-December in the SBoB.

The advanced analytical and numerical techniques developed in this study can be extended to interannual timescales. Horii et al. (2008) found that the subsurface signals preceded the surface signals by 3 months during the initial stage of the positive IO dipole event (Saji et al. 1999) in 2006, which hints a vertical propagation. The subsurface upwelling phase of wind-forced KWs potentially affects the development of the IO dipole by altering sea surface temperature (Chen et al. 2016). The propagation and reflection process of these wave energy is also responsible for the significant intraseasonal oscillation in the equatorial eastern IO (Chen et al. 2015b) and within the Bay of Bengal (Chen et al. 2018). Future work in this direction will enhance our knowledge of the highly influential interactions and exchanges between the tropical and extratropical regions (particularly during active phases of the IO dipole) and will therefore contribute to a better understanding of climate variation.

\section{Appendix}

\subsection{Linear Ocean Model (LOM)}

We simulated climatological variability in the IO using a linear ocean model (LOM). The model has been discretized in a spherical coordinate system with a grid spacing of $(1 / 4)^{\circ}$ in both zonal and meridional directions. The model domain extends from 35 to $120^{\circ} \mathrm{E}$ and from $25^{\circ} \mathrm{S}$ to $20^{\circ} \mathrm{N}$ and adopts realistic coastlines except for the lack of connection to the Southern Ocean and the Pacific Ocean. The LOM is written for the development of zonal velocity $u^{(n)}(x, y, t)$, meridional velocity $v^{(n)}(x, y$, $t$ ), and geopotential $\Phi^{(n)}(x, y, t)$ associated with the generic $n$-th baroclinic mode. For each baroclinic mode these are related through

$$
\begin{aligned}
& u_{t}^{(n)}-f v^{(n)}+\Phi_{x}^{(n)}= \alpha^{(n)} \frac{\tau^{x}}{\rho_{0} \sqrt{h_{\text {mix }} H_{\text {bottom }}}} \\
&+\mathrm{SGS}^{x}, \\
& v_{t}^{(n)}+f u^{(n)}+\Phi_{y}^{(n)}= \alpha^{(n)} \frac{\tau^{y}}{\rho_{0} \sqrt{h_{\text {mix }} H_{\text {bottom }}}} \\
&+\mathrm{SGS}^{y}, \\
& \Phi_{t}^{(n)}+\left(c^{(n)}\right)^{2}\left(u_{x}^{(n)}+v_{y}^{(n)}\right)=0,
\end{aligned}
$$

where horizontal and temporal partial derivatives are denoted by subscripts $x, y$, and $t$ respectively. $f$ denotes the Coriolis coefficient. $\rho_{0}=1027 \mathrm{~kg} / \mathrm{m}^{3}$ is the reference value of water density. The vector $\left(\tau^{x}, \tau^{y}\right)$ represents wind stress. The mode-dependent parameters $\alpha^{(n)}$ and $c^{(n)}$ have been calculated in the present study using the climatological annual mean stratification of the tropical IO (explained later in this section). The definition of $\alpha^{(n)}$ is described in detail in the Appendix of LA20. The values of $\alpha^{(n)}$ and $c^{(n)}$ used in the present study are given in Table 1 . The present study defines the mixed layer depth as the depth where temperature is lower than the surface by $0.2^{\circ} \mathrm{C}$ and calculated it using Argo float data. From the resulting annual mean of mixed layer depth in the tropical IO, we set $h_{\text {mix }}=35 \mathrm{~m}$. $H_{\text {bottom }}=5500 \mathrm{~m}$ represents the reference depth of the bottom of the ocean in the tropical IO. The subgrid-scale terms, which are labelled as SGS in (9a) and (9b), indicate the effect of lateral eddy viscosity applying the Smagorinsky et al. (1965) scheme with a nondimensional coefficient of 0.1 after squaring.

Reconstruction of vertical profile based on the output of LOM is done by using the eigen vectors, as in previous studies. While LA20 executed a series of numerical experiments focusing on the first three baroclinic modes which assumed no motion at the bottom, the present study has investigated the first six baroclinic modes under the assumption of a free-slip bottom boundary (Chelton and Schlax 1996; see below). The first six modes explain about $80 \%$ of baroclinic kinetic energy fraction in the equatorial regions of a global ocean reanalysis, as shown by Fig. 1 in Toyoda et al. (2021). The Sturm-Liouville equation for the baroclinic normalmode decomposition associated with a stratified ocean may be written as

$$
\left(F_{z}^{(n)} / N^{2}\right)_{z}=\frac{-1}{\left(c^{(n)}\right)^{2}} F^{(n)}
$$

where $F^{(n)}=F^{(n)}(z)$ and $c^{(n)}$ are the eigenfunction and non-rotating gravity wave speed, respectively, of the $n$-th baroclinic mode. The symbol $N=N(z)$ in (10) is the buoyancy frequency which we have given based on the vertical profiles of climatological annual mean salinity 
and temperature in the tropical $\mathrm{IO}\left(20^{\circ} \mathrm{S}-20^{\circ} \mathrm{N}, 40-\right.$ $\left.110^{\circ} \mathrm{E}\right)$ from the World Ocean Atlas. We have solved (10) using a Neumann boundary condition, $F_{z}^{(n)}=0$, at both the surface and bottom of the ocean and obtained $c^{(n)}=2.63 \mathrm{~m} / \mathrm{s}, 1.57 \mathrm{~m} / \mathrm{s}, 0.956 \mathrm{~m} / \mathrm{s}, 0.706 \mathrm{~m} / \mathrm{s}, 0.557 \mathrm{~m} / \mathrm{s}$, and $0.467 \mathrm{~m} / \mathrm{s}$ for the first six baroclinic modes. The vertical profiles of the eigenfunctions are shown in Figure 9 in Appendix where $\int_{-H_{\text {bottom }}}^{0}\left(F^{(n)}\right)^{2} d z=H_{\text {bottom }}$ and bottom depth $H_{\text {bottom }}=5500 \mathrm{~m}$. The parameter $\alpha^{(n)}$ of wind forcing partition in (9a)-(9b) has been determined in the same manner as that in LA20.

McCreary (1984) demonstrated that the vertical propagation related to equatorial waves can be described by the sum of baroclinic modes. The present study has reconstructed the vertical structure of the tropical IO by using the results of model experiment associated with fundamental six baroclinic modes. Quantities in the depth coordinate, such as geopotential $\Phi(x, y, z, t)$, zonal velocity $u(x, y, z, t)$, meridional velocity $v(x, y, z, t)$, and vertical velocity $w(x, y, z, t)$, are obtained as

$$
\begin{aligned}
\Phi(x, y, z, t)= & \sum_{n} \Phi^{(n)}(x, y, t) F^{(n)}(z), \\
u(x, y, z, t)= & \sum_{n} u^{(n)}(x, y, t) F^{(n)}(z), \\
v(x, y, z, t)= & \sum_{n} v^{(n)}(x, \mathrm{y}, t) F^{(n)}(z), \\
w(x, y, z, t)= & \sum_{n} \frac{-1}{N^{2}}\left[\frac{\partial}{\partial t} \Phi^{(n)}(x, y, t)\right] \\
& \times\left[\frac{\partial}{\partial z} F^{(n)}(z)\right],
\end{aligned}
$$

and have been applied to each of the 100 snapshots obtained from the final year of model output.

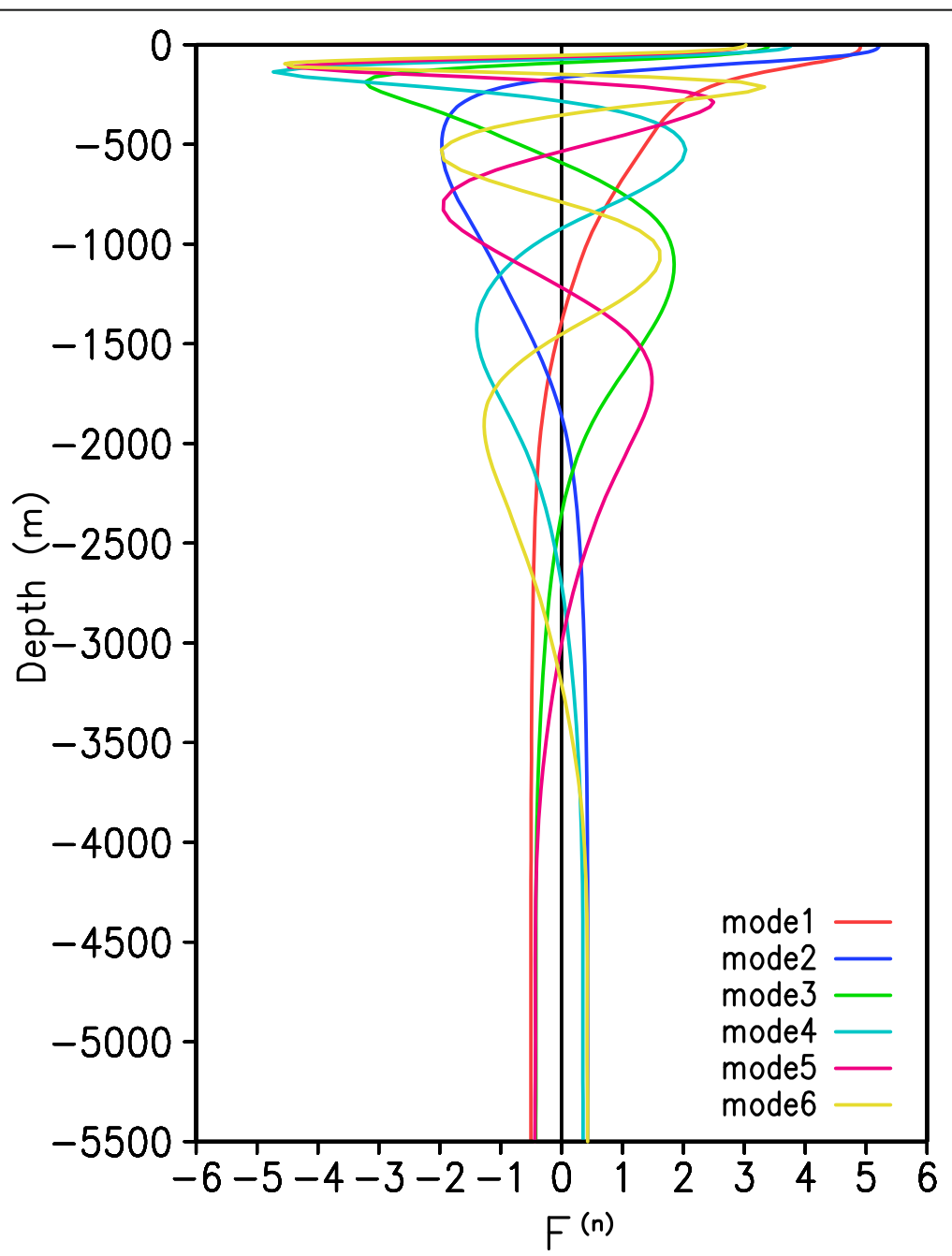

Fig. 9 The vertical profiles of eigenfunctions $F^{(n)}$ associated with fundamental six baroclinic modes in the tropical Indian Ocean, calculated by solving the Sturm-Liouville problem. Details are in the Appendix 
Wave energy Eq. (3a) should include wind forcing and dissipation terms. These terms yield the energy flux potential defined in (8a)-(8b) in a climatological equilibrium state of wave energy. The depth-integral of the wind forcing term is written as

$$
\begin{aligned}
& u(x, y, 0, t) \tau^{x}+v(x, y, 0, t) \tau^{y} \\
& \quad=\sqrt{\frac{H_{\text {bottom }}}{h_{\text {mix }}}} \sum_{n} \alpha^{(n)}\left[u^{(n)}(x, y, t) \tau^{x}+v^{(n)}(x, y, t) \tau^{y}\right]
\end{aligned}
$$

which is referred to as wind input (see contours in Fig. 6a, b and color shading in Fig. 7).

\section{Abbreviations}

AGC17: Aiki et al. 2017; ECMWF ERA-40: European Centre for Medium-Range Weather Forecasts Reanalysis; IGWs: Inertia-gravity waves; IO: Indian Ocean; KWs: Kelvin waves; LA20: Li and Aiki 2020; LOM: Linear ocean model; OGCM: Ocean General Circulation Model; OFES: Ocean General Circulation Model For the Earth Simulator; PF: Pressure flux; RGWs: Mixed Rossby-gravity waves; RWs: Rossby waves; SGS: Subgrid scale; SBoB: Southern Bay of Bengal

\section{Supplementary Information}

The online version contains supplementary material available at https://doi. org/10.1186/s40645-021-00432-9.

Additional file 1. The extension of the formulation of Aiki et al. (2017).

\section{Authors' contributions}

ZL performed the numerical experiments and carried out analysis. HA proposed the topic and conceived the study. MN and TO helped improve the integrity and construction of the manuscript. The authors read and approved the final manuscript.

\section{Funding}

This study was supported by Japan Society for the Promotion of Science (JSPS) KAKENHI Grant Numbers $18 \mathrm{H} 03738$ and 15H02129.

\section{Availability of data and materials}

The set of model outputs obtained during the last year of each of the six experiments performed in the present study will be archived at both https:// www.diasjp.net/en/ and http://cidas.isee.nagoya-u.ac.jp/databases/index. shtml.en upon publication of this manuscript. A number of datasets were retrieved from the Asia-Pacific Data Research Center at the University of $\mathrm{Ha}$ wai'i (http://apdrc.soest.hawaii.edu). These include temperature and salinity data from the World Ocean Atlas 2013 for the calculation of gravity wave phase speed, mixed-layer depth data from the Argo products, wind velocity data from the European Centre for Medium-Range Weather Forecasts Reanalysis (ECMWF ERA-40) for estimation of climatological wind forcing, and output of velocity and zonal stress from the Ocean General Circulation Model For the Earth Simulator (OGCM OFES).

\section{Declarations}

\section{Competing interests}

The authors declare that they have no competing interest.

\section{Author details}

${ }^{1}$ Graduate School of Environmental Studies, Nagoya University, Furo-cho, Chikusa-ku, Nagoya 464-8601, Japan. ${ }^{2}$ Institute for Space-Earth Environmental Research, Nagoya University, Furo-cho, Chikusa-ku, Nagoya 464-8601, Japan. ${ }^{3}$ Application Laboratory, Japan Agency for Marine-Earth Science and Technology, Kanazawa-ku, Yokohama 236-0001, Japan. ${ }^{4}$ Research Institute for Global Change, Japan Agency for Marine-Earth Science and Technology, Yokosuka 237-0061, Japan.
Received: 24 December 2020 Accepted: 1 June 2021

Published online: 13 July 2021

\section{References}

Aiki H, Greatbatch RJ, Claus M (2017) Towards a seamlessly diagnosable expression for the energy flux associated with both equatorial and midlatitude waves. Prog Earth Planet Sci 4(1):11. https://doi.org/10.1186/s40645017-0121-1

Brandt P, Eden C (2005) Annual cycle and interannual variability of the middepth tropical Atlantic Ocean. Deep Sea Res 52(2):199-219. https://doi.org/1 0.1016/j.dsr.2004.03.011

Chelton DB, Schlax MG (1996) Global observations of oceanic Rossby waves. Science 272(5259):234-238. https://doi.org/10.1126/science.272.5259.234 https://www.jstor.org/stable/2889630

Chen G, Han W, Li Y, McPhaden MJ, Chen J, Wang W, Wang D (2017) Strong intraseasonal variability of meridional currents near $5^{\circ} \mathrm{N}$ in the eastern Indian Ocean: characteristics and causes. J Phys Oceanogr 47(5):979-998. https://doi. org/10.1175/JPO-D-16-0250.1

Chen G, Han W, Li Y, Wang D (2016) Interannual variability of equatorial Eastern Indian Ocean upwelling: local versus remote forcing. J Phys Oceanogr 46(3): 789-807. https://doi.org/10.1175/JPO-D-15-0117.1

Chen G, Han W, Li Y, Wang D, McPhaden MJ (2015a) Seasonal-to-interannual time-scale dynamics of the equatorial undercurrent in the Indian Ocean. J Phys Oceanogr 45(6):1532-1553. https://doi.org/10.1175/JPO-D-14-0225.1

Chen G, Han W, Li Y, Wang D, Shinoda T (2015b) Intraseasonal variability of upwelling in the equatorial Eastern Indian Ocean. J Geophys Res 120(11): 7598-7615. https://doi.org/10.1002/2015JC011223

Chen G, Han W, Li Y, Yao J, Wang D (2019) Intraseasonal variability of the equatorial undercurrent in the Indian Ocean. J Phys Oceanogr 49(1):85-101. https://doi.org/10.1175/JPO-D-18-0151.1

Chen G, Han W, Zhang X, Liang L, Xue H, Huang K, He Y, Li, Wang D (2020) Determination of spatiotemporal variability of the Indian equatorial intermediate current. J Phys Oceanogr 50:3095-3108. https://doi.org/10.1175/ JPO-D-20-0042.1

Chen G, Li Y, Xie Q, Wang D (2018) Origins of Eddy kinetic energy in the Bay of Bengal. J Geophys Res 123(3):2097-2115. https://doi.org/10.1002/2017JC013455

Dewitte B, Reverdin G (2000) Vertically propagating annual and interannual variability in an OGCM simulation of the tropical Pacific Ocean in 1985-94. J Phys Oceanogr 30:1562-1158. https://doi.org/10.1175/1520-0485(2000)030< 1562:VPAAIV > 2.0.CO;2

Ding $\mathrm{H}$, Keenlyside NS, Latif M (2009) Seasonal cycle in the upper equatorial Atlantic Ocean. J Geophys Res 114(C9):C09016. https://doi.org/10.1029/2 $009 J C 005418$

Fu LL (2007) Intraseasonal variability of the equatorial Indian Ocean observed from seasurface height, wind, and temperature data. J Phys Oceanogr 37(2): 188-202. https://doi.org/10.1175/JPO3006.1

Gill AE (1982) Atmosphere-ocean dynamics. Academic, London, p 662

Han W (2005) Origins and dynamics of the 90-day and 30-60-day variations in the equatorial Indian Ocean. J Phys Oceanogr 35(5):708-728. https://doi. org/10.1175/JPO2725.1

Hayes SP, Milburn HB (1979) On the vertical structure of velocity in the eastern equatorial Pacific. J Phys Oceanogr 10:633-635. https://doi.org/10.1175/15200485(1980)010<0633:OTVSOV >2.0.CO;2

Horii T, Hase H, Ueki I, Masumoto Y (2008) Oceanic precondition and evolution of the 2006 Indian Ocean dipole. Geophys Res Lett 35(3):L03607. https://doi. org/10.1029/2007GL032464

Huang K, Han W, Wang D, Wang W, Xie Q, Chen J, Chen G (2018a) Features of the Equatorial Intermediate Current associated with basin resonance in the Indian Ocean. J Phys Oceanogr 48(6):1333-1347. https://doi.org/10.1175/JPOD-17-0238.1

Huang K, McPhaden MJ, Wang D, Wang W, Xie Q, Chen J, Shu Y, Wang Q, Li J, Yao J (2018b) Vertical propagation of mid-depth zonal currents associated with surface wind forcing in the equatorial Indian Ocean. J Geophys Res 123(10):7290-7307. https://doi.org/10.1029/2018JC013977

Huang K, Wang D, Han W, Feng M, Chen G, Wang W, Chen J, Li J (2019) Semiannual variability of middepth zonal currents along $5^{\circ} \mathrm{N}$ in the eastern Indian Ocean: characteristics and causes. J Phys Oceanogr 49(10):2715-2729. https://doi.org/10.1175/JPO-D-19-0089.1

Ishizaki H, Nakano H, Nakano T, Shikama N (2014) Evidence of equatorial Rossby wave propagation obtained by deep mooring observations in the western 
Pacific Ocean. J Oceanogr 70(6):463-488. https://doi.org/10.1007/s10872-0140247-3

Johnson GC (2011) Deep signatures of southern tropical Indian Ocean annual Rossby waves. J Phys Oceanogr 41(10):1958-1964. https://doi.org/10.1175/ JPO-D-11-029.1

Kessler WS, McCreary JP (1993) The annual wind-driven Rossby-wave in the subthermocline equatorial Pacific. J Phys Oceanogr 23:1192-1207. https://doi. org/10.1175/1520-0485(1993)0231192:TAWDRW2.0.CO;2

Large WG, Pond S (1981) Open ocean momentum flux measurements in moderate to strong winds. J Phys Oceanogr 11:324-336. https://doi.org/10.11 75/1520-0485(1981)011<0324:OOMFMI>2.0.CO;2

Li Z, Aiki H (2020) The life cycle of annual waves in the Indian Ocean as identified by seamless diagnosis of the energy flux. Geophys Res Lett 47(2): e2019GL085670. https://doi.org/10.1029/2019GL085670

Longuet-Higgins HC (1964) On group velocity and energy flux in planetary wave motion. Deep Sea Res 11:35-42. https://doi.org/10.1016/001 1-7471(64)91080-0

Lucas R, Firing E (1985) The annual Rossby wave in the central equatorial Pacific Ocean. J Phys Oceanogr 15(1):55-67. https://doi.org/10.1175/1520-0485(1 985)0150055:TARWIT2.0.CO;2

Luyten JR, Roemmich DH (1982) Equatorial currents at semiannual period in the Indian-Ocean. J Phys Oceanogr 12:406-413. https://doi.org/10.1175/1520-04 85(1982)012<0406:ECASAP>2.0.CO;2

Luyten JR, Swallow JC (1976) Equatorial undercurrents. Deep Sea Res 23:9991001. https://doi.org/10.1016/0011-7471(76)90830-5

Mark RJ, Huang B (2004) The Rossby wave as a key mechanism of Indian Ocean climate variability. Deep Sea Res Part I 51(12):2123-2136. https://doi.org/10.1 016/j.dsr.2004.06.005

Masumoto $Y$ et al (2004) A fifty-year eddy-resolving simulation of the world ocean: preliminary outcomes of OFES (OGCM for the Earth Simulator). J Earth Simulator 1:35-56

Matsuno T (1966) Quasi-geostrophic motions in the equatorial area. J Meteo Soc Japan 44:25-43. https://doi.org/10.2151/jmsj1965.44.1_25

McCreary JP (1984) Equatorial beams. J Mar Res 42(2):395-430. https://doi.org/1 $0.1357 / 002224084788502792$

McPhaden MJ (1982) Variability in the central equatorial Indian-Ocean. I: ocean dynamics. J Mar Res 40:157-176

McPhaden MJ, Ripa P (1990) Wave-mean flow interactions in the equatorial ocean. Annu Rev Fluid Mech 20:167-205. https://doi.org/10.1146/annurev. fl.22.010190.001123

Miyama T, McCreary JP, Sengupta D, Senan R (2006) Dynamics of biweekly oscillations in the equatorial Indian Ocean. J Phys Oceanogr 36(5):827-846. https://doi.org/10.1175/JPO2897.1

Nagura M (2018) Annual Rossby waves below the pycnocline in the Indian Ocean. J Geophys Res 123:9405-9415. https://doi.org/10.1029/2018jc014362

Nagura M, McPhaden MJ (2010a) Wyrtki jet dynamics: seasonal variability. J Geophys Res 115:C07009. https://doi.org/10.1029/2009JC005922

Nagura M, McPhaden MJ (2010b) Dynamics of zonal current variations associated with the Indian Ocean dipole. J Geophys Res 115(C11):C11026. https://doi. org/10.1029/2010JC006423

Nagura M, McPhaden MJ (2016) Zonal propagation of near-surface zonal currents in relation to surface wind forcing in the equatorial Indian Ocean. J Phys Oceanogr 46(12):3623-3638. https://doi.org/10.1175/jpo-d-16-0157.1

Ogata T, Aiki H (2019) The pathway of intraseasonal wave energy in the tropical Indian Ocean as identified by a seamless diagnostic scheme. SOLA 15:262267. https://doi.org/10.2151/sola.2019-047

Pujiana K, McPhaden MJ (2020) Intraseasonal Kelvin waves in the equatorial Indian Ocean and their propagation into the Indonesian seas. J Geophys Res 125(5):e2019JC015839. https://doi.org/10.1029/2019JC015839

Reppin J, Schott FA, Quadfasel D (1999) Equatorial currents and transports in the upper central Indian Ocean: annual cycle and interannual variability. J Geophys Res Oceans 104(C7):15495-15514. https://doi.org/10.1029/1 999JC900093

Rothstein LM, Moore DW, McCreary JP (1985) Interior reflections of a periodically forced equatorial Kelvin wave. J Phys Oceanogr 15(7):985-996. https://doi. org/10.1175/1520-0485(1985)015<0985:IROAPF>2.0.CO;2

Saji NH, Goswami BN, Vinayachandran PN, Yamagata T (1999) A dipole mode in the tropical Indian Ocean. Nature 401:360-363. https://doi.org/10.1038/43854

Schott FA, McCreary JP (2001) The monsoon circulation of the Indian Ocean. Prog Oceanogr 51(1):1-123
Smagorinsky J, Manabe S, Holloway JL (1965) Numerical results from a nine-level general circulation model of the atmosphere. Mon Weather Rev 93:727-768. https://doi.org/10.1175/1520-0493(1965)0930727:NRFANL2.3.CO;2

Song Q, Aiki H (2020) The climatological horizontal pattern of energy flux in the tropical Atlantic as identified by a unified diagnosis for Rossby and Kelvin waves. J Geophys Res 125:e2019JC015407. https:/doi.org/10.1029/2019JC015407

Thierry V, Mercier H, Treguier AM (2006) Seasonal fluctuations in the deep central equatorial Atlantic Ocean: Aa data-model comparison. Ocean Dyn 56(5-6): 581-593. https://doi.org/10.1007/s10236-005-0045-y

Toyoda T, Nakano H, Aiki H, Ogata T, Fukutomi Y, Kanno Y, Urakawa LS, Sakamoto K, Yamanaka G, Nagura M (2021) Energy flow diagnosis of ENSO from an ocean reanalysis. J Clim:1-86. https://doi.org/10.1175/JCLI-D-200704.1

Wyrtki K (1973) An equatorial jet in the Indian Ocean. Science 181(4096):262-264. https://doi.org/10.1126/science.181.4096.262

Yanai M, Maruyama T (1966) Stratospheric wave disturbances propagating over the equatorial Pacific. J Met Soc Japan 44(5):291-294. https://doi.org/10.2151/ jmsj1965.44.5_291

Yu X, McPhaden MJ (1999) Seasonal variability in the equatorial Pacific. J Phys Oceanogr 29:925-947. https://doi.org/10.1175/1520-0485(1999)0290925: SVITEP2.0.CO;2

Yuan DL, Han WQ (2006) Roles of equatorial waves and western boundary reflection in the seasonal circulation of the equatorial Indian Ocean. J Phys Oceanogr 36(5):930-944. https://doi.org/10.1175/JPO2905.1

Zanowski H, Johnson GC (2019) Semiannual variations in 1,000-dbar equatorial Indian Ocean velocity and isotherm displacements from Argo data. J Geophys Res Oceans 124(12):9507-9516. https://doi.org/10.1029/2019JC01 5342

\section{Publisher's Note}

Springer Nature remains neutral with regard to jurisdictional claims in published maps and institutional affiliations.

\section{Submit your manuscript to a SpringerOpen ${ }^{\circ}$ journal and benefit from:}

- Convenient online submission

- Rigorous peer review

- Open access: articles freely available online

High visibility within the field

- Retaining the copyright to your article

Submit your next manuscript at $\boldsymbol{\nabla}$ springeropen.com 